Management of.

EH: $\mathrm{X}$

Radioactive Mastes

Stored in

Underground Tanks

aํ Haniord

April, 1970
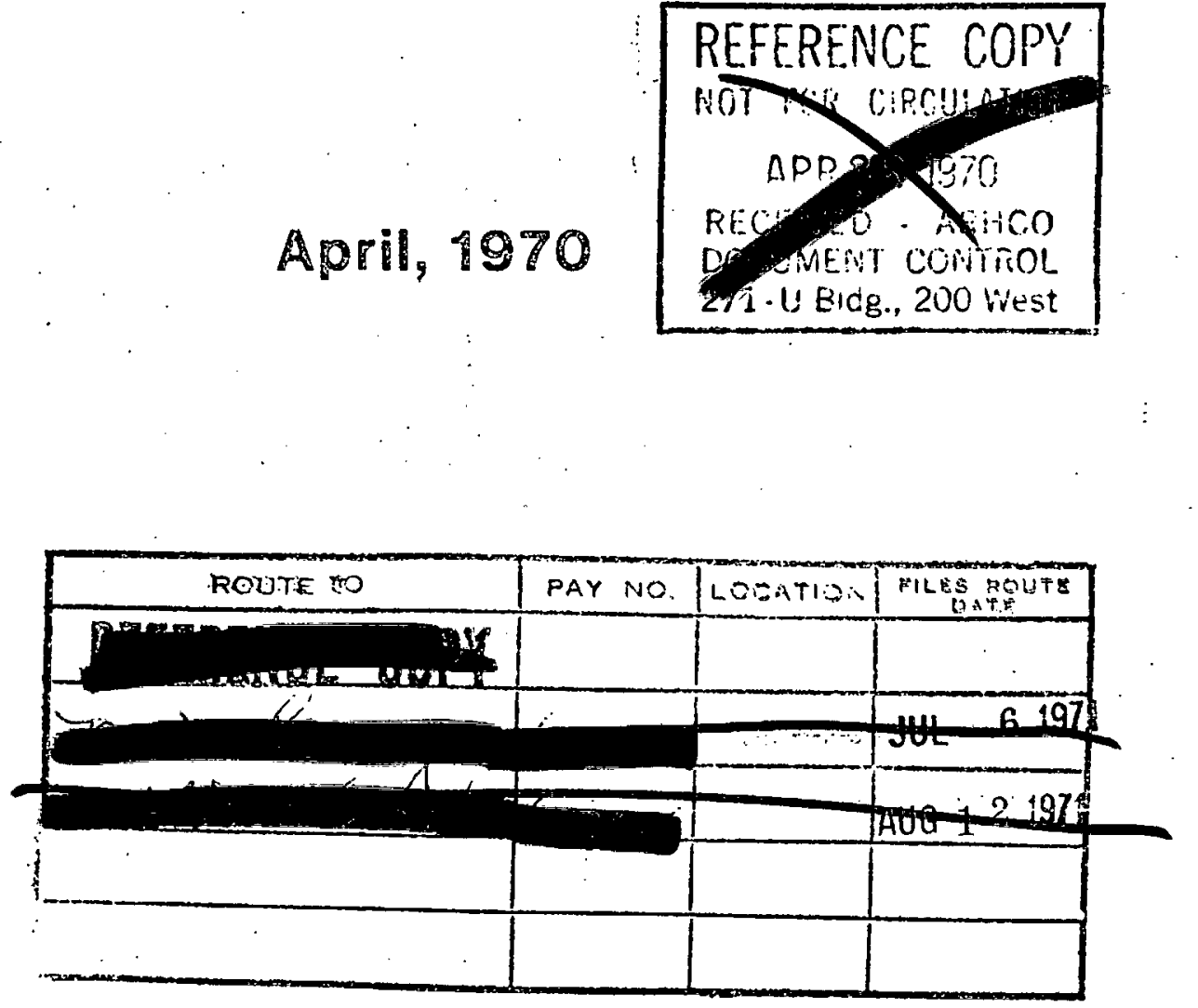

This report was prepared as an account of work sponsored by the United States Government. Neither the United States nor the United States Atomic Energy Commission, nor any of their employees, nor any of their contractors, subcontractors, or their employees, makes iny warranty, express or implied, or assumes any makes any warranty, express or implied, or assumes any legal liability or responsibility for the accuracy, completeness or usefulness of any information, apparatus,
product or process disclosed, or represents that its use would not infringe privately owned rights.

\section{Atlantic Richfield Hanford Company}

Richland, Washington

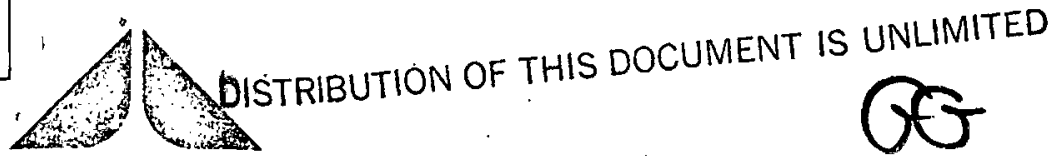




\section{DISCLAIMER}

This report was prepared as an account of work sponsored by an agency of the United States Government. Neither the United States Government nor any agency Thereof, nor any of their employees, makes any warranty, express or implied, or assumes any legal liability or responsibility for the accuracy, completeness, or usefulness of any information, apparatus, product, or process disclosed, or represents that its use would not infringe privately owned rights. Reference herein to any specific commercial product, process, or service by trade name, trademark, manufacturer, or otherwise does not necessarily constitute or imply its endorsement, recommendation, or favoring by the United States Government or any agency thereof. The views and opinions of authors expressed herein do not necessarily state or reflect those of the United States Government or any agency thereof. 


\section{DISCLAIMER}

Portions of this document may be illegible in electronic image products. Images are produced from the best available original document. 


\title{
MANAGEMENT OF RADIOACTIVE WASTES \\ STORED IN UNDERGROUND TANKS AT HANFORD
}

\author{
Compiled by
}

R. W. Harvey

Apri1, 1970

(This revision supersedes in entireiy ARH-R-43 Rev., "A Review of Tank Farm Management Practices." The purpose of this revision is to correct minor typographical errors, provide a more meaningful title, and to clarify the text in some areas.)

Atlantic Richfield Hanford Company

Richland, Washington 


\section{TABLE OF CONTENTS}

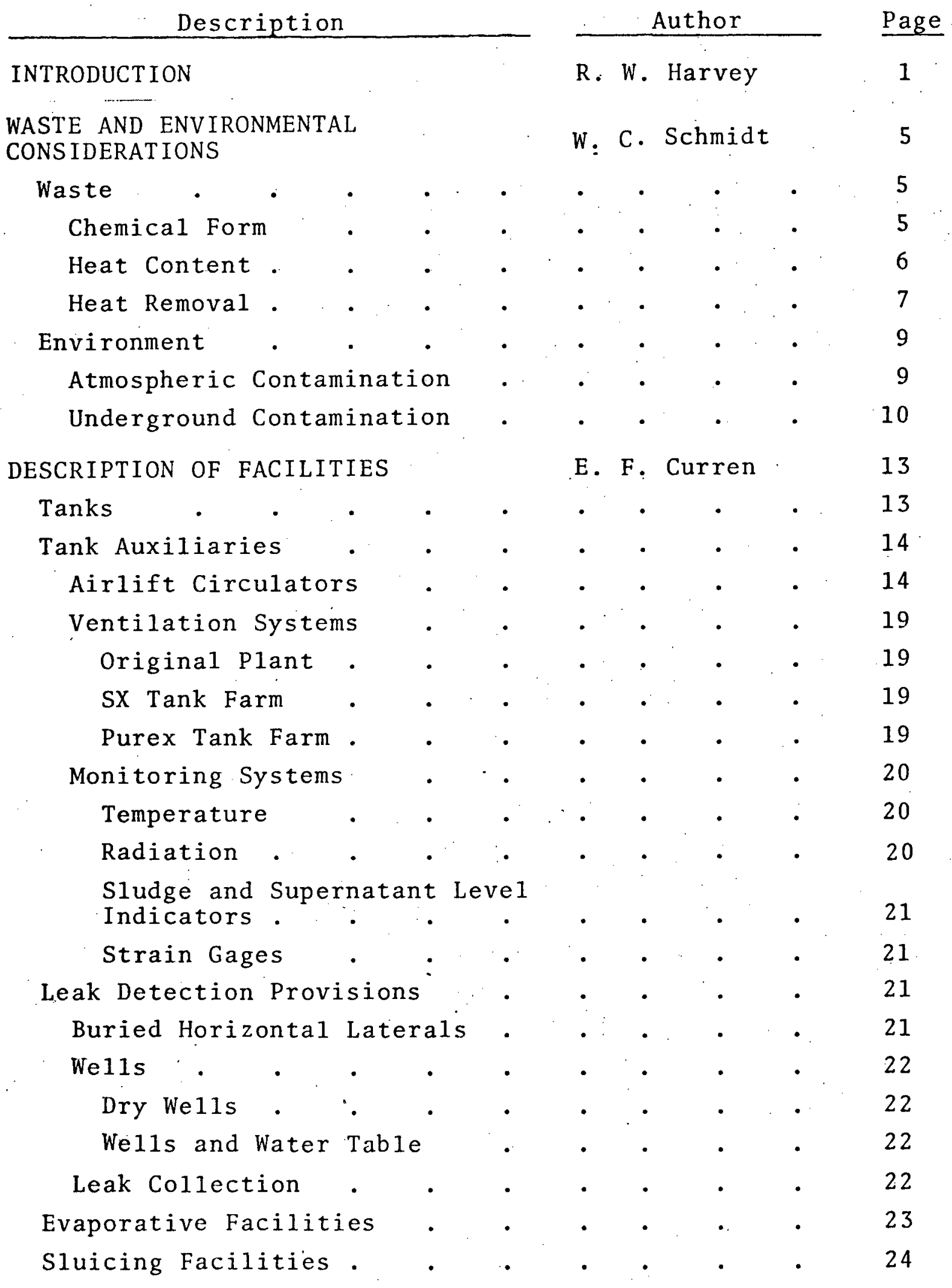


OPERATING PRACTICE

R: E. Roberts

Nonboiling Waste Receiving

Operations

Boiling waste Receiving

Operations

Surveillance Actions Employed

Nonboiling Waste Tanks

Boiling Waste Tanks

LEAK EXPERIENCE

W. L. Godfrey

35

104-U Tank

113-SX Tank

106-TY Tank

101-U Tank

105-TY Tank

39

108-SX Tank

105-A Tank

107 -SX Tank

109-SX Tank

115 -SX Tank

112 -SX Tank

40

40

41

41

41

42

RATIONALE FOR DECISION

R. E. Tomlinson

43

Sludge Temperature Abnormal1y $\mathrm{High}$

Recognition.

Probable Cause

Principal Considerations

Basic Approach

Leaking Tank - Nonboiling Waste

Recognition.

Probable Cause

Principal Considerations.

Basic Approach

Leaking Tank - Self-Boiling Wastes

Recognition.

Probable Cause

Principal Considerations 


\section{ADDENDUM}

Stress and Strength Analysis for Waste Tank Structures

P. Hatch

A. 1

Soil Loads

Active Soil Loading .

Reactive Soil Pressure

Footing and Slab Pressures

Temperature .

Hydrostatic Head and Specific

Gravity

Vapor Pressure and Vacuum

Earthquake Induced Forces

Combined Stress Evaluation

Hoop Tension at Cylinder

Footing Juncture.

Bending Stresses at Juncture

Possible Shear-Tension

Fracture of Cylinder.

Dome Loads

Mode1 Tests, Experiments and

Observations

105-A Scale Mode1 of Bottom

Liner

108-SX Footing

101-A and 107-SX Dome Cores

Micro-Concrete Scale Model Tests

Stress Corrosion Cracking Tests

101-A Leak Detection

Future Evaluations

References 


\section{LIST OF FIGURES}

1. Characteristics of Stored Waste and As-Built Tank Dimensions

2. Composite Section - A Farm Tank

3. Composite Section - AX Farm Tank

4. Composite Section - AY Farm Tank

\section{LIST OF TABLES}

1. Waste Storage Tanks at Hanford

2. Design Parameters (Through AX Tank Series)

3. Underground Waste Storage Tank Leak Experience 
ARH-R-43 Rev. 2

\author{
MANAGEMENT OF RADIOACTIVE WASTES \\ STORED IN UNDERGROUND TANKS AT HANFORD
}

\title{
INTRODUCTION
}

This publication describes past and present methods used to store radioactive wastes in underground tank farms at the Hanford Plant. Presentation of the significant features involved in the management of these stored wastes should be helpful to other plant organizations with related waste handling obligations.

The total complex of waste storage tanks at Hanford includes 149 tanks, ranging in capacity from 54,500 to $1,000,000 \mathrm{gal}$. These tanks are grouped in twelve farms located in the 200 East and 200 West Areas. The oldest tank farms, 241-B, C, T, and $U$ were constructed in 1943-44 concurrently with the bismuth phosphate plants. The first waste was routed to tank storage in December 1944. Additional tanks in separate tank farm locations were constructed during the period 1946 to 1964 (See Table 1) to accommodate the wastes accumulating from continuing plant operation. Currently under construction are two 1,000,000-gal tanks. These tanks will be designated as the 241-AY tank farm, the thirteenth tank farm at Hanford.

The basic containment employed in the design of the tanks in the first twelve farms was the provision of a reinforced concrete shell with a carbon steel liner. During the past $11 \mathrm{yr}$, leaks have been confirmed in 11 of the 149 tanks 1:sted in Table 1. These leaks have occurred in seven tanks storing self-boiling wastes and in four tanks holding nonboiling wastes. An improved tank design to provide more protection against possible release to the environment of radioactive materials was developed prior to the current two-tank construction project. These latter two tanks will have a double steel liner within the concrete shel1, thereby providing an extrabarrier 
TABLE 1. Waste Storage Tanks at Hanford

\begin{tabular}{|c|c|c|c|c|}
\hline Farm. & $\begin{array}{l}\text { Tanks } \\
\text { Per } \\
\text { Farm } \\
\end{array}$ & $\begin{array}{c}\text { Capacity } \\
\text { Per Tank, } \\
\text { Gal } \\
\end{array}$ & $\begin{array}{c}\text { Capacity } \\
\text { Per Farm, } \\
\text { Gal } \\
\end{array}$ & $\begin{array}{c}\text { Year } \\
\text { Constructed } \\
\end{array}$ \\
\hline A & 6 & $1,000,000$ & $6,000,000$ & $1954-55$ \\
\hline$A X$ & 4 & $1,000,000$ & $4,000,000$ & $1963-64$ \\
\hline $\mathrm{B}$ & 16 & $\begin{array}{r}54,500(4) \\
-530,000(12)\end{array}$ & $6,578,000$ & $1943-44$ \\
\hline $\mathrm{BX}$ & 12 & 530,000 & $6,360,000$ & $1946-47$ \\
\hline $\mathrm{BY}$ & 12 & 758,000 & $9,096,000$ & $1948-49$ \\
\hline $\mathrm{C}$ & 16 & $\begin{aligned} 54,500 & (4) \\
530,000 & (12)\end{aligned}$ & $6,578,000$ & $1943-44$ \\
\hline S & 12 & 758,000 & $9,096,000$ & $1950-51$ \\
\hline SX & 15 & $1,000,000$ & $15,000,000$ & $1953-54$ \\
\hline $\mathrm{T}$ & 16 & $\begin{array}{c}54,500(4) \\
.530,000 \quad(12)\end{array}$ & $6,578,000$ & $1943-44$ \\
\hline $\mathrm{TX}$ & 18 & 758,000 & $13,644,000$ & $1947-48$ \\
\hline TY & 6 & 758,000 & $4,548,000$ & $1951-52$ \\
\hline $\mathrm{U}$ & 16 & $\begin{array}{c}54,500(4) \\
530,000(12)\end{array}$ & $6,578,000$ & $1943-44$ \\
\hline Total & 149 & & $94,056,000$ & \\
\hline
\end{tabular}

against release of radioactive liquids plus recovery facilities for any liquid which might collect in the annular space between the liners.

A. spare tank policy providing emergency storage reserve for self-boiling wastes was documented in August 1968. This policy requires a minimum of one unoccupied tank as a spare in each tank farm complex where self-boiling wastes are stored. Double-1ined tanks were preferred, but were not scheduled to be available until 1970. Use of the single-lined tanks as 
spares was a necessity. If they had not been used previously, one was considered sufficient. If only used single-lined tanks were available, then one unoccupied tank plus additional equivalent reserve capacity was required.

For nonboiling waste, at least $2,000,000$ gal. of useful storage reserve are maintained at all times.

The following sections cover the nature of wastes created at Hanford, the complexities introduced by the heat generation capacity of the wastes, and the mechanisms which guard against environmental contamination. The various waste storage facilities are described, along with their principal auxiliaries. Routine operating practices and surveillance methods employed are detailed. For those 11 tanks, where the evidence has confirmed the existence of leaks, a brief service history for each tank is presented plus a summary of the actions taken in each case to maintain control of the wastes. The main presentation concludes with the rationale for decision when events occur that require corrective action.

The addendum summarizes stress and strength analyses for waste tank structures completed by the I11inois Institute of Technology. 
THIS PAGE

WAS INTENTIONALLY

LEET BLANK 


\section{WASTE AND ENVIRONMENTAL CO'NSIDERATIONS}

\section{WASTE}

\section{Chemical Form}

Self-boiling, high-level waste is stored in underground tanks as an alkaline slurry. Neutralization to $\mathrm{pH} 8$ or greater with sodium hydroxide and/or sodium carbonate is required to keep the corrosion of the carbon steel tanks to a minimum. This neutralization precipitates a major portion of the reactor fission products. The ferric ion is also precipitated and is an excellent carrier for additional fission products that could exist in the supernatant.

The major salts in the waste are sodium nitrate and sodium nitrite. Minor cations are iron, aluminum, manganese, uranium, and lead; minor anions are sulfate, carbonate, phosphate, and hydroxide. Precipitated with these salts are most of the reactor fission products. At the time of discharge from the Purex plant, the major heat-producing fission products are

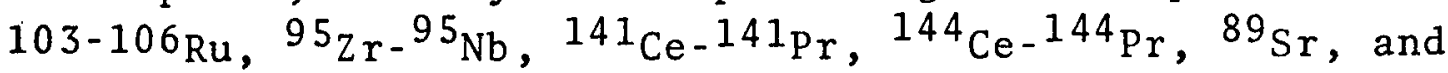
$90 \mathrm{Sr}-90 \mathrm{Y}$, and $137 \mathrm{Cs}$. After $3 \mathrm{yr}$ of decay the major remaining heat producers are ${ }^{137} \mathrm{Cs},{ }^{90} \mathrm{Sr},{ }^{106} \mathrm{Ru}$, and ${ }^{144} \mathrm{Ce}$; and after $10 \mathrm{yr}$ of decay on $1 \mathrm{y}{ }^{90} \mathrm{Sr}$ and ${ }^{137}$.Cs remain in significant quantities. These fission products comprise only a small fraction of the chemical salts in the tanks.

Most of the ${ }^{137} \mathrm{Cs}$ is in the supernatant solution as are rhodium, palladium and technetium. The remaining fission products are associated with the sludge. Approximately 10 percent of the cesium precipitates or is occluded with the ferric hydroxide. It is soluble and can be removed from the sludge by water washing without dissolving the remaining fission products.

The large quantities of fission products in the wastes release sufficient radiation energy to induce several chemical 
reactions. The most prevalent reactions are the radiolysis of water and the reduction of nitrate ion:

$$
\begin{aligned}
& 2 \mathrm{H}_{2} \mathrm{O} \rightarrow \mathrm{H}_{2}+\mathrm{H}_{2} \mathrm{O}_{2}+2 \mathrm{H}_{2}+\mathrm{O}_{2} . \\
& 2 \mathrm{NO}_{3}^{-} \rightarrow 2 \mathrm{NO}_{2}^{-}+\mathrm{O}_{2} .
\end{aligned}
$$

The formation of nitrite ion minimizes the stress corrosion effect of the nitrate ion in the wastes.

Organic compounds, such as the long-chained hydrocarbons that are used in the Purex process and which are entrained to a siight extent in the waste, are converted to carbon dioxide and water by radiolysis:

$$
\text { Organic } \rightarrow \mathrm{CO}_{2}+\mathrm{H}_{2} \mathrm{O}
$$

The carbon dioxide, in turn, is converted to either the bicarbonate or carbonate ion by reaction with the excess sodium hydroxide :

$$
\mathrm{CO}_{2}+\mathrm{OH}^{-} \rightarrow \mathrm{HCO}_{3}^{-}+\mathrm{OH}^{-} \rightarrow \mathrm{CO}_{3}^{-}+\mathrm{H}_{2} \mathrm{O} \text {. }
$$

Additional carbon dioxide is introduced into the tank by the air which is used as the motivating force for the air lift circulators. The carbon dioxide associated with the air ( 0.03 volume percent) is likewise converted either to the bicarbonate or to the carbonate ion by reacting with the excess hydroxide ion as shown in the preceding chemical reaction.

There are other types of wastes from various process stages but they do not contain long half-life, high-heatproducing radionuclides in sufficient quantities to cause selfboiling. These include aluminum and zirconium coating removal wastes and organic wash solutions.

\section{Heat Content}

Self-boiling in process wastes is caused solely by the presence of radioactive fission products in sufficient con-. centration. At discharge from the Purex plant, this waste has 
a heat content of approximately $125 \mathrm{Btu} / \mathrm{hr} / \mathrm{gal}$. Batchwise additions of this waste to 1,000,000-gal storage tanks at close intervals result in a boil-off rate gradually approaching $15 \mathrm{gpm}$. Normally, the solubility limit of the sodium ion has been reached prior to the time the $15 \mathrm{gpm}$ boil-off rate is attained and insufficient heat transfer from the precipitated sludge requires that waste from additional fuel reprocessing be routed to another tank.

At discharge from the Purex plant, the supernatant contains about 1 percent of the heat associated with high level waste. This heat comes from the decay of ${ }^{134} \mathrm{Cs}$ and ${ }^{137} \mathrm{Cs}$. After $10 \mathrm{yr}$ of decay, the heat of the waste has decreased to less than 2 percent of the total at discharge; the supernatant comprises approximately 46 percent of the remaining heat.

At discharge from the Purex plant, the sludge contains 99 percent of the fission product heat. This heat comes primarily from the decay of 89 and $90 \mathrm{Sr}, 95_{\mathrm{Zr}-\mathrm{Nb}}$, 103 and ${ }^{106} \mathrm{Ru}-\mathrm{Rh}$, and 141 and $144 \mathrm{Ce}-\mathrm{Pr}$. After $10 \mathrm{yr}$ of decay, the only remaining radioactive isotope is $90 \mathrm{Sr}$ which accounts for approximately 54 percent of the remaining heat in the wastes. Heat Removal

The transfer of heat from an underground storage tank is by conduction and evaporation. Thermal conductivity of the surrounding soil is relatively low, but during initial heatup and low thermal output, this soil is a large heat sink which absorbs the heat up to a rate of $500,000 \mathrm{Btu} / \mathrm{hr}$ declining with time to the range of 50,000 to $100,000 \mathrm{Btu} / \mathrm{hr}$. Heat generation within the tanks sufficiently increases 1iquid temperature to cause appreciable evaporation. Most of this vapor is either transferred to the condenisers with in-1eaking air or recondenses on the dome of the tank. Heat generation above $500,000 \mathrm{Btu} / \mathrm{hr}$ causes the solution to boil. The temperature remains relatively constant except for slight increases 
as the boiling point is raised by the increasing salt concentration. The heat is removed by vaporization of the liquid which is condensed in water-cooled condensers provided for this purpose.

The thermal conductivity of the sludge is relatively low. After a few inches of sludge collects in the bottom of the tank, removal of heat by only thermal conductivity through the sludge would result in abnormally high temperatures. The settled sludge is permeable and the void space within this sludge cake is filled with supernatant solution. Increased temperature of the liquid in intimate contact with the sludge over the remaining supernatant causes convection currents. These convection currents start a percolation action between the hotter liquid and the surrounding cooler liquid which, in turn, removes the heat from the sludge. The convection currents are of sufficient magnitude to keep some sludge suspended in the supernatant. As the fission products decay and the total heat becomes less, the convection currents diminish and more of the sludge settles.

In addition to the mild circulation caused by the thermal gradients, air lift circulators are operated to agitate the solution above the sludge. A constant interchange of liquid from the top to the bottom minimizes the formation of superheated liquid (relative to its boiling point at atmospheric pressure) which could flash to vapor as it rises in the tank and is subjected to less hydrostatic pressure. If a large amount of superheated 1 iquid is allowed to accumulate, and it starts to rise, the rate of steam generation can increase sufficiently to pressurize the tank up to $30 \mathrm{in}$. of water. An additional benefit from the air circulators is that the agitation provided keeps additional sludge in suspension. The sludge in suspension is easily cooled by intimate contact with. the surrounding liquid. The sludge level in the tank 
is minimized so that the heat transfer which is dependent on the permeability of the sludge is maintained.

The permeability of the sludge appears to be influenced by its chemical composition. Laboratory tests of synthetic sludges indicate that the permeability is inversely proportional to the concentration of the sodium ion in the supernatant. This was further proved to be a function of the viscosity of the solution. Increased sulfate and carbonate concentrations greater than nitrate, nitrite, and hydroxide concentrations also decrease the permeability.

ENVIRONMENT

The storage of mobile high level waste is closely controlled to prevent the release of the biologically harmful radionuclides to the immediate environs and more importantly to the surrounding population. Engineered systems are provided to prevent radioactive pollution of the water table and the atmosphere. The most sophisticated systems are installed in the A-AX farms and are described below.

Atmospheric Contamination

Pollution of the atmosphere with radionuclides from the boiling waste tanks is prevented by maintaining a slight vacuum on each of these tanks. This pressure differential between the tank interior and the surrounding atmosphere assures that any small leaks around tank risers, pumps; sluicers, transfer lines, etc., will cause a flow of air into the tank and will prevent migration of gases, vapors or particles outward into the atmosphere.

The tank vapors are decontaminated by a condenser, two demisters, and a high efficiency filter prior to release through a $50-\mathrm{ft}$ stack. A monitor is provided to measure the amount of radioactivity released to the atmosphere with an associated alarm to indicate any abnormal emissions. With a stack 50 feet above ground level, tenfold dilution factors 
are available to minimize local contamination. The tank farm stack is located near the center of the Hanford reservation about 25 miles from the nearest population center. The remoteness minimizes the potential for affecting the general public in the unlikely event of an accidental radioactivity emission, by increasing the dilution before any contact with emitted radionuclides could occur.

Undergound Contamination

The boiling high level waste tanks are located at varying distances from main separations plants.. They are reinforced concrete structures with a steel liner and are buried in the ground to provide shielding from the intense radioactivity of the stored waste slurry. The surrounding soil is a sandsilt-gravel layered matrix which extends downward 150 to $250 \mathrm{ft}$ to the groundwater. The soil has capacity for absorbing additional liquid up to 10 percent of its volume. With these depths to groundwater, a leak of 50,000 gal from a single point would contaminate a large volume of soil but none of the liquid would reach the groundwater. Any spreading of the 1iquid, or if the liquid were released from dispersed sources, would tend to increase the quantity of liquid that could be so held.

In addition to its 1 iquid retention capability, the soil has ion exchange properties for chemically sorbing ${ }^{90} \mathrm{Sr},{ }^{137} \mathrm{Cs}$ and other elements. As the liquid from a leak percolates downward through the soil, the isotopes of primary concern $\left({ }^{90} \mathrm{Sr}\right.$ and $\left.{ }^{137} \mathrm{Cs}\right)$ are sorbed on the soil. The solubility of plutonium in the alkaline supernatant is so low that its migiation from a leaking tank would be insignificant; in addition, plutonium is very tightly sorbed by the clay fractions of the, soil, providing a large additional safety factor in preventing the migration of plutonium. These soil ion exchange properties greatly lessen the probability of groundwater contamination in the event of a tank leak. 
The flow of groundwater toward the Columbia River is relatively slow. It requires approximately $10 \mathrm{yr}$ for the water underneath the 200 East Area to reach the river. The ion exchange properties of the soil delay the rate of migration of ${ }^{90} \mathrm{Sr}$ and ${ }^{137} \mathrm{Cs}$ to $1 / 100$ and $1 / 1000$ of the groundwater rate. 


\section{THIS PAGE WAS INTENTIONALLY LEFT BLANK}




\section{DESCRIPTION OF FACILITIES}

TANKS

The original tank farms $T, U, B$, and $C$ featured tanks with dished bottoms and a $17-\mathrm{ft}$ operating depth. The BX farm tanks were built to the original tank design.

Second generation tank design is embodied in the S, BY, $T X$, and TY tank farms and is essentially the same as the original tanks except for increased capacity and a 23 -ft operating depth.

The third and fourth generation tanks are represented by the SX and A design with the operating depth increasing to $31 \mathrm{ft}$ and the A tanks going to a flat instead of a dished bottom.

The fifth generation tanks, in the AX farm, were essentially the same as the A tank design with the addition of a grid of drain slots beneath the steel liner bottom.

The grids function to collect potential tank leakage. This is then diverted to a leak detection we11. The grids also serve as an escape route for free water formed as it is released from the concrete grout during initial heating of the tank. The following table illustrates essential design parameters through the AX tank series.

\section{TABLE 2. Design Parameters (Through AX Tank Series)}

\section{Concrete}

fc (comp.) psi 3,000

fc (tension) psi 300 Density ( $1 \mathrm{~b} / \mathrm{ft} 3)$ 150

Coefficient of Therma1 Expansion (in. $/{ }^{\circ} \mathrm{F}$ ) 0.0000065

Stee 1

fs (bending) psi

fs (tension) psi

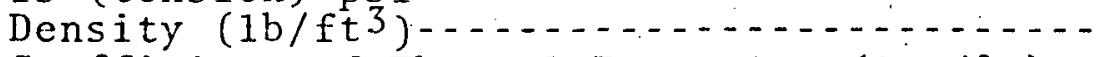

Coefficient of Thermal Expansion (in. $/{ }^{\circ} \mathrm{F}$ ) 20,000 16,000

480 Soi 1

Density $\left(1 \mathrm{~b} / \mathrm{ft}^{3}\right)$ 110 Allowable Soil Bearing ( $\left.1 \mathrm{~b} / \mathrm{ft}^{2}\right)$ 6,000

Foundation Modulus ( 1 b/in.2) 200 
TABLE 2. Design Parameters (Through. AX Tank Series) (contd) Liquid

Specific Gravity (max: hot) -....... $1.2-2.0$

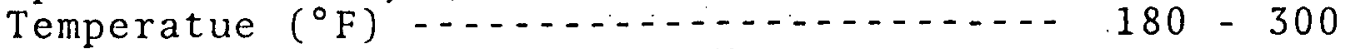

Allowable Vapor Pressure in $\mathrm{H}_{2} \mathrm{O}$

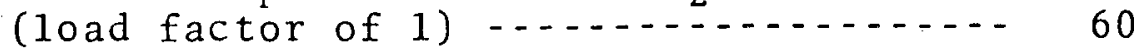

Alkalinity $(\mathrm{pH}) \ldots \ldots \ldots$

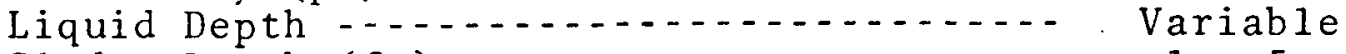

Sludge Depth $(\mathrm{ft}) \ldots \ldots \ldots$

The AY tank design represents a departure from the basic design reflected in all previous tanks. This design features a heat-treated, stress-relieved primary steel liner and a nonstress-relieved outer steel liner, both inside the reinforced concrete shel1.

The characteristics of the wastes stored in each of the tank farms and the as-built dimensions of the tanks in each generation are shown in Figure 1. Figures 2, 3 and 4 represent composite sections of the A, AX, and AY farm tanks, respectively.

\section{TANK AUXILIARIES}

Tank auxiliaries are provided to prevent or minimize the escape of radioactive material to the environment. The more significant auxiliary systems are briefly discussed below.

\section{Airlift Circulators}

Airlift circulators are installed in boiling tanks to promote mixing of the supernatant. By maintaining motion within the body of liquid, the circulators minimize superheat buildup and, consequently, prevent bumping.

The circulators are long, open cylinders of varying lengths immersed in the tank's contents. An air line discharging at the base of the cylinders causes a flow of solution from bottom to top of the cylinder. This moves fresh solution from the bottom of the tank to the supernatant layer above. 
WASTE

\section{CHARACTERISTICS}

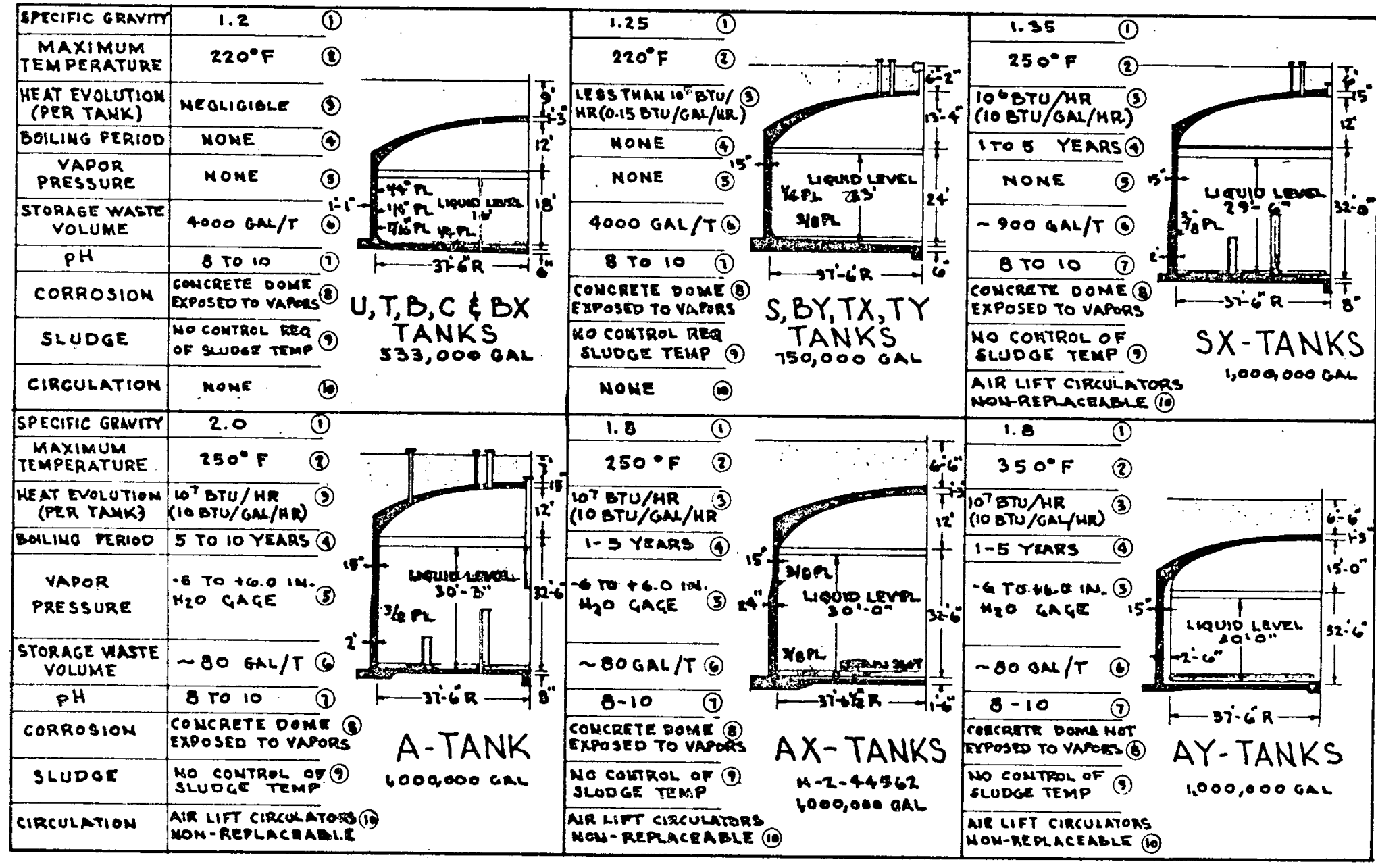

FIGURE 1. Characteristics of Stored Waste and As-Buizt Tank Dimensions 


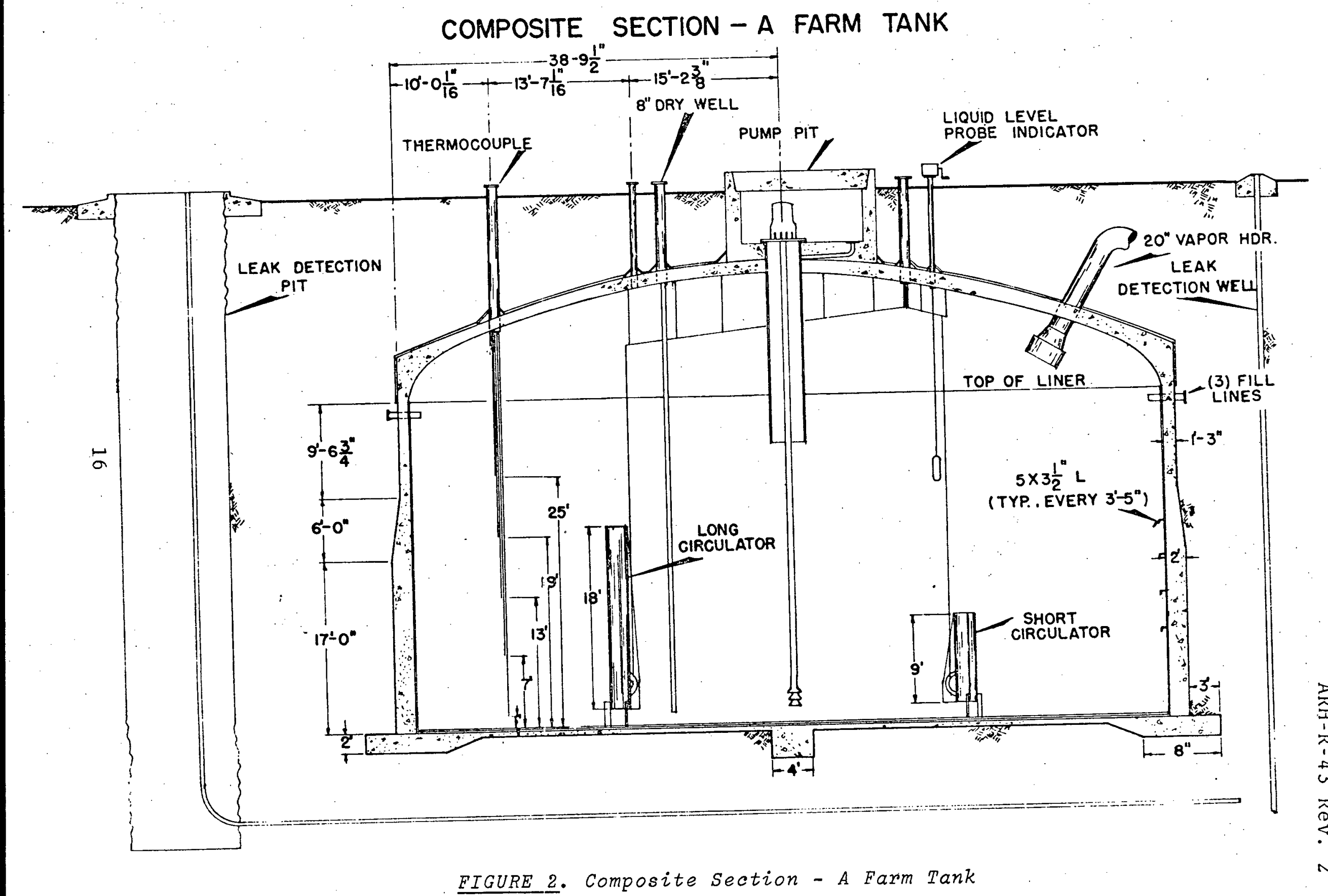

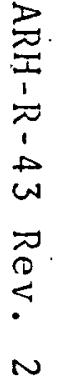




\section{ming \\ COMPOSITE SECTION - AX FARM TANK}

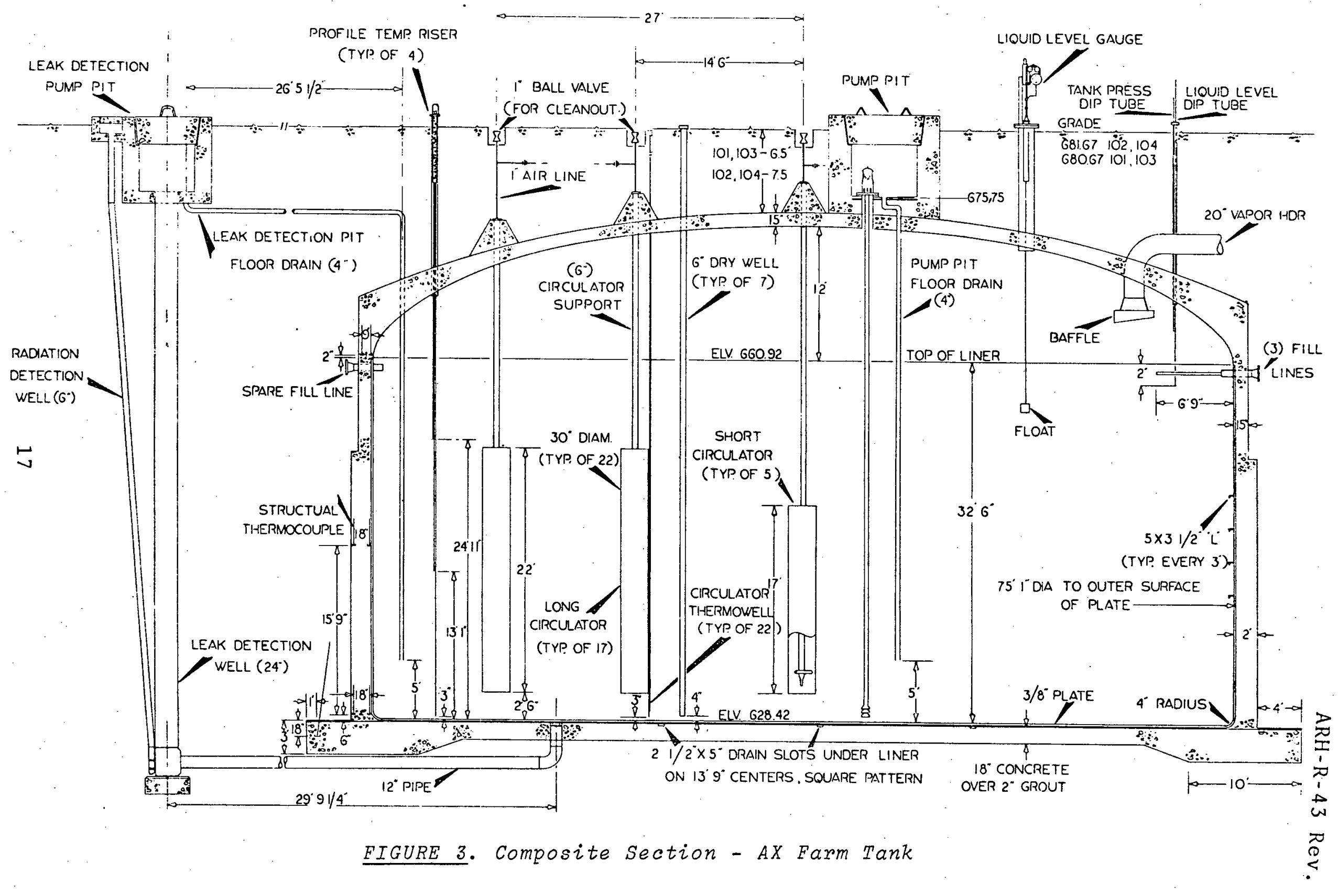




\section{COMPOSITE SECTION-AY FARM TANK}

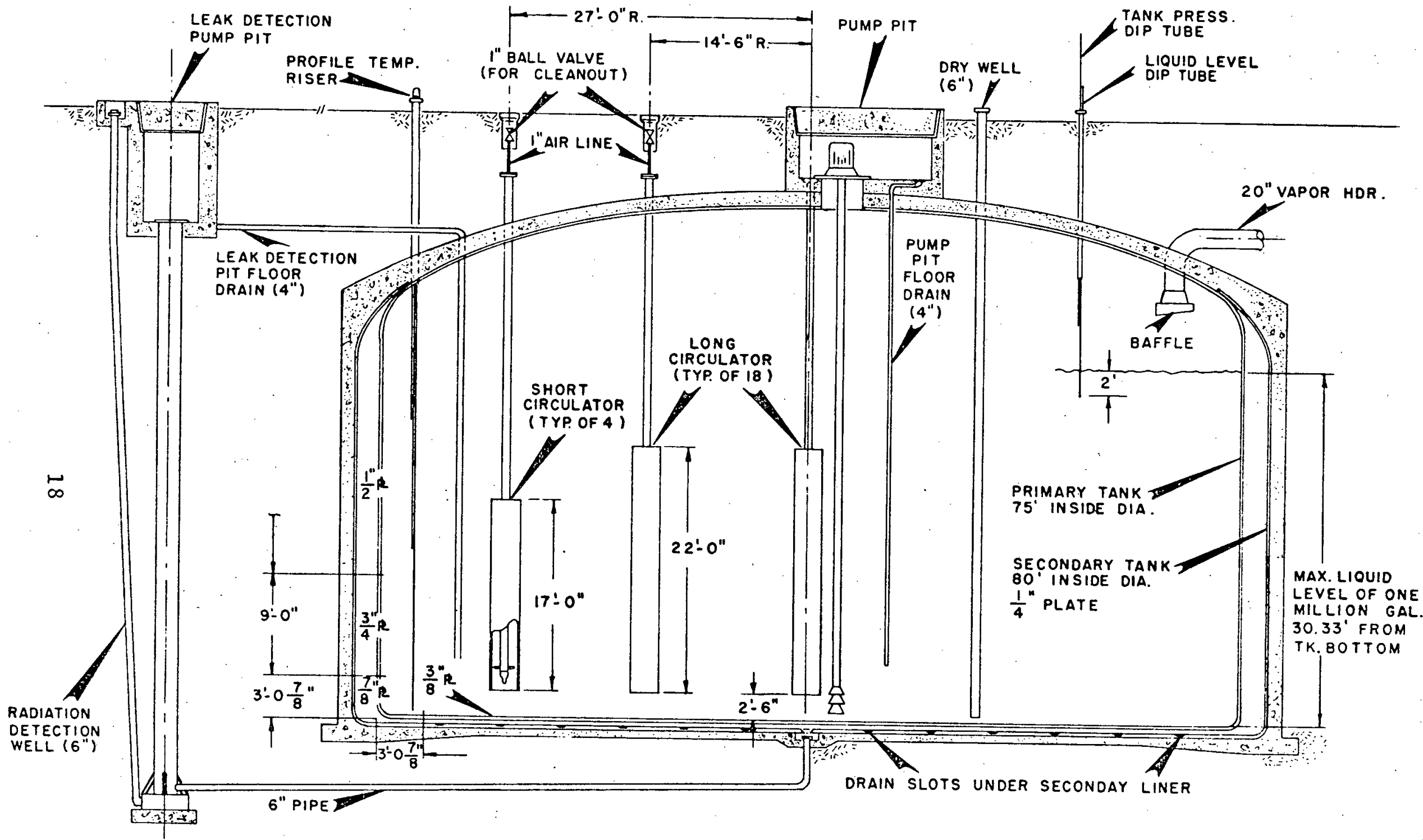

FIGURE 4. Composite Section - AY Farm Tank 
Ventilation Systems

Original Plant

The waste storage tanks in the T, U, B, C, S, SX, TX and TY (first and second generation) tank farms were equipped with air-cooled condensers of the multi-tube air-fin type vented directly to atmosphere. These condensers were adequate for the waste temperatures and vapor loads encountered in the original operation. (Approximately $180^{\circ} \mathrm{F}$ for sludge and supernatants.)

SX Tank Farm

The SX tanks were the first tanks designed for boiling service and were expected to boil from 1 to $5 \mathrm{yr}$. The heat load on the SX system increased as wastes self-concentrated and it was necessary to install air-1ift circulators to prevent bumping. This increased the vapor load on the ventilation system. From a practical standpoint, the atmosphere in the tanks must be considered as saturated at the ambient temperature $\left(\sim 180^{\circ} \mathrm{F}\right)$, and condensibles must be removed before noncondensibles may be filtered and discharged to atmosphere. Dependent upon the status of the tank contents, condensate may either be discharged to a crib or returned to the tank to maintain liquid level.

\section{Purex Tank Farm}

The. A and AX tank farms have a common ventilation system to which the AY tank farm is being connected. Backup facilities are provided by the $A$ farm vent system.

In order to preclude release of contanination to the environment, it is necessary to maintain a slight negative pressure on the waste tanks. A highly reliable exhaust system maintains this slight vacuum. Two electric fans are connected in parallel with one fan always in the standby position. In case of a fan failure, the standby fan is autonatically energized. Both of these fans are electrically driven. In the 
case of an electrical failure, emergency power is supplied by a steam-driven turbine-generator in the area steam plant. A diesel-powered emergency generator is also available in the tank farm.

Loading on the ventilation system consists of air in-leakage in pump pits, in drains to the tank from service pits, in filling lines and from the air introduced by the airlift circulators. The combined A-AX-AY ventilation system has a maximum capacity of $\sim 4000 \mathrm{cfm}$.

Monitoring Systems

Monitoring devices and systems are used to determine the status of the stored wastes, to measure the potential effects of the stored wastes upon the tank structures, and to indicate real or potential operating problems involving tank failure.

\section{Temperature}

In relating. to the waste tank structures themselves, the AX and AY tank designs provided for the installation of thermocouples in various locations within the concrete she11, within the sludge and under the tanks. Using these thermocouples temperature profiles may be taken as a means of determining thermal stresses within the shell and sludge and to indicate the need for changes in the mode of operation of the tanks.

\section{Radiation}

The detection and measurement of radiation gives direct information relating to tank integrity, and $i n$, the event of tank failure is used to locate the region or regions of failure. Monitoring wells located in the older tank farms are specifically designed for this purpose.

Radiation profiles, also temperature patterns, as a measure of tank condition are determined by passing detection aevices through piping laterals located in the soil beneath the $A$ and $S X$ tanks. 
Subsurface radiation detection in the AX and AY tank farms is provided in the leak collection facilities described at the bottom of page 22 .

\section{Sludge and Supernatant Leve1 Indicators}

Monitoring nonboiling tank supernatant and sludge levels indicates possible changes of conditions within the tank. Electrode tapes are used to determine liquid leve1; metal plate "floats" ( 3 to 6 in. in diameter) which will sink until they contact the sludge are used to determine sludge levels. Also, a waste sludge level detector measures liquid and sludge levels by radiation intensity.

\section{$\underline{\text { Strain Gages }}$}

Strain gages have been installed on the AY tank farm tanks to provide a measure of any stress change occurring while the tanks are in service. The strain gages are welded directly to the inner tank liner.

\section{LEAK DETECTION PROVISIONS}

Equipment provided for the prompt detection and confirmation of leaks in underground waste storage tanks consists primarily of different types of access channels beside and underneath the tanks through which instruments may travel to monitor radiation level and temperature. The fluctuation of liquid level in self-boiling wastes makes the use of contact probes or floats impractical; however, float devices are used for the detection of bumping.

A brief description of the major leak detection devices follows.

\section{Buried Horizontal Laterals}

The buried horizontal lateral system for radiation detection and temperature measurement in the 241-A and SX tank farms consists of $12-\mathrm{ft}$ diameter caissons sunk approximately $70 \mathrm{ft}$ 
below grade. From each caisson three laterals are bored horizontally under each tank bottom approximately $10 \mathrm{ft}$ below the base pad elevation.

The insertion of temperature and radiation probes into each lateral for a given tank provides profiles which are used in the evaluation of tank integrity and for the determination of changing conditions in the tank contents.

We11s

The we11s used are of two types: 1) open end dry wells sunk in groups in a tank farm, and 2) wells extending into the water table below a tank farm site.

Dry We11s

Each tank is ringed with a series of these wells, which are 6 in. in diameter, bottom open ended, and sunk to a $76-\mathrm{ft}$ depth below grade. The opening of the casing is approximately $23 \mathrm{ft}$ below the elevation of the base slab of the tanks. A total of 38 detection we11s, for example, each located approximately $10 \mathrm{ft}$ from a tank, serve the six-tank 241-A tank farm complex. The dry wells can accommodate portable gamma detection devices.

\section{Wells and Water Table}

These wells are customarily sunk to levels below the surface of the water table underlying the tank farm site. Routine monitoring of these wells should spot radionuclides released to the soil in sufficient quantity to reach the water table.

\section{Leak Collection}

The most recently constructed tank farm (AX) provides a system of drain channels in the concrete base slab immediately below the carbon steel tank liner. They drain to a 24 in., 60-ft deep we11 from which leakage can be pumped. A radiation detection well is located adjacent to this sump-type system. 
The two tanks presently under construction (AY tank farm) also have drain channels in the insulating material installed between the steel and concrete prior to the thermal stressrelieving operation. These channels could carry leakage to the annular space between the inner and outer 1iners. Detection during operation is provided by conductivity probes in the annulus and by radiation alarms in the exhaust system. EVAPORATIVE FACILITIES

Greater safety in containment of nonboiling liquid wastes is obtained by converting them to the solid form. This is being carried out by two methods of evaporation, ultimately leaving a solid salt cake in these underground tanks. One method makes use of in-tank heating to remove water. Both heated air and electric immersion heaters are used. The other method involves the transfer of the liquid waste to a standard evaporator located in a separate building. Bottoms from this evaporator are returned to the underground waste storage tanks where salts crystaliize out and residual supernatant liquors are recycled through other waste tanks for re-evaporation.

In-tank heating is accomplished by in-tank solidification units designated ITS No. 1 and ITS No. 2, both located in the BY tank farm in 200 East Area. The $242-T$ evaporator in the 200 West Area, operated on a previous waste volume reduction program; has been reactivated following capacity increasing modifications.

The immobilization procedure, whatever the method of evaporation used, consists of the following steps:

(1) Concentrate sufficient waste into a single tank such that, upon cooling, the majority of the contents would be solidifed.

(2) Cool the tank.

(3) Remove or sorb any residual aqueous phase. 
(4) Fill the vapor space with a solid (dry sand, grout, etc.) which will support the dome in the event of failure.

(5) Continue surveillance of the system.

\section{SLUICING FACILITIES}

Sluicing operations were first employed at Hanford for the removal of sludges in connection with the $\mathrm{TBP} P \mathrm{Plant}$ recovery of stored neutralized uranium nitrate wastes from the operation of the wartime bismuth phosphate separation process.

Sluicing operations are in use at the present time for the removal of stored sludge for the recovery of strontium.

Sludge is removed from a tank by pumping off the supernatant and exposing the sludge. High pressure pumps ( 180 psig) in the 244-AR vault transfer water (or supernatant) to the tank being sluiced through specially designed nozzles. As the sludge is broken into a slurry, it is transferred to a holding tank, settled, and the supernatant is recycled to remove additional sludge. 


\section{OPERATING PRACTICE}

NONBOILING WASTE RECEIVING OPERATIONS

The tanks in the nine nonboiling tank farms are of three sizes: $54,500 \mathrm{gal}, 530,000 \mathrm{gal}$, and $758,000 \mathrm{ga}$. The 530,000-gal and the $750,000-$ gal tanks are arranged in cascades of three, four, or six tanks; i.e., the tanks are arranged in such a manner that when the first tank in a cascade is filled, it overflows to the second tank, then to the third tank, etc. As various programs have been initiated through the years, many of the overflows between tanks in the various cascades have been removed, modified, or blanked. A number of the tanks are equipped with air-cooled reflux condensers. Dry wells located within the tank farms are used to monitor the soil for radioactivity, thus serving as a leak detection system. These dry wells extend to a depth of about $75 \mathrm{ft}$, which is several feet below the bottom of the tanks.

The routing of nonboiling liquid waste from the operating building to the tank farms is done by means of underground lines and diversion boxes where selected underground piping is interconnected by jumpers. Leaks occurring in the diversion boxes or into the surrounding line encasement drain to catch tanks which are then jetted to the large underground storage tanks. Active catch tanks and waste storage tanks are inventoried daily by taking electrode readings of the liquid level; inactive tanks are inventoried once a week.

Upon notification from the operating building to the tank farm that a batch of waste is ready to be pumped to underground storage, the tank farm operator determines: (a) that a satisfactory routing is in place from the operating building to the designated receiving tank, and (b) that the receiving tank has sufficient space to accommodate the transfer. If all conditions 
are satisfactory for the transfer, the tank farm operator notifies the operating building, and the transfer is started. After completing the transfer, the volume, obtained by difference from electrode measurements of the liquid level of the receiving tank, is logged for future reference.

BOILING WASTE RECEIVING OPERATIONS

There are three boiling waste tank farms: $A, A X$, and $S X$, containing six, four, and fifteen waste storage tanks, respectively. A fourth tank farm, AY, consisting of two 1,000,000-gal tanks, is present1y under construction in 200 East Area.

The SX tank farm, used for storing Redox salt wastes, was the first to be equipped for handling boiling waste solutions, although not all of the SX tanks could accommodate self-boiling wastes. Of the 15 tanks in the farm, only tanks 105, and 107 through 115, were equipped to handle self-boiling wastes.

Both the A and AX tank farms were built to store Purex wastes. The capacity of these tanks, as well as SX tanks, is $1,000,000$ gal. Vapors from the boiling action or selfconcentration are routed through headers to condensers which are vented to the atmosphere through filters. Condensate is either discarded to cribs or returned to the waste tank where it is used to maintain the desired liquid level.

In the boiling waste tanks, heat is generated when the fission products decay radioactively. Most of the heat generated is dissipated by boiling the supernatant, although a small amount of heat is conducted to the ground. The rate of heat generation in a tank is dependent upon the quantity of fission products present which, in turn, is dependent upon:

- The characteristics of the fuel being processed in the Purex plant in terms of:

- Reactor power level (MW/T)

- Integrated exposure (MWd/T)

- Cooling time since reactor discharge. 
- Rate of tank filling in terms of associated tons of uranium production per day.

- The period of time during which a tank receives waste.

- Integrated age of the waste in the tank.

After constructing a new waste storage tank for selfboiling wastes, a minimum of 7 in. of water is added to the tank to prevent the bottom liner from buckling under conditions of negative pressure maintained on the tank. A tank vacuum in excess of 6 in. of water is impossible because of a water seal located in the tank farm vent header.

Several weeks before placing the tank in routine service for receipt of waste, the tank is filled above the short circulators with water and preheated with an external heat source (e.g., steam coil) to minimize the thermal stress in the structure. This can be accomplished by heating at either a uniform rate of temperature change or by an incremental increase, provided the incremental rate does not exceed $40^{\circ} \mathrm{F}$ in any one day nor an average of $5^{\circ} \mathrm{F}$ per day. After the tank reaches boiling temperature and starts to receive waste routinely, the operating temperature is controlled between $220^{\circ} \mathrm{F}$ and $250^{\circ} \mathrm{F}$, with a maximum allowable sludge temperature less than $300^{\circ} \mathrm{F}$. At this point, the steam coil may or may not be turned off, depending upon the heat requirements of the tank. For example, if the boil-off rate is low but the waste additions are large, the steam coil would continue to be used to supply supplemental heat.

Each boiling waste tank is equipped with air lift circulators to minimize superheat accumulation and to delay the settling of sludge by providing mild, vertical agitation. At SX and A farms, each boiling waste tank contains four air lift circulators. Each $\mathrm{AX}$ farm tank has 22 circulators. Air flow to the circulators is manually controlled and measured by individual rotameters. Although the minimum air flow requirement is 
$20 \mathrm{ft}^{3} / \mathrm{min}$ to each tank (for hydrogen dilution) normally each of the circulators in operation will be set between 5 and $10 \mathrm{ft}^{3} / \mathrm{min}$. If required, however, the flow can be increased to a maximum of $20 \mathrm{ft}^{3} / \mathrm{min}$ per circulator. Water is connected to each of the air supply lines to the circulators, and they are flushed routinely to prevent plugging of the air distributor by the saturated salt solutions in the tank.

During the construction of the AX tank farm, two diverter stations were provided for routing the Purex wastes to the tank farms. The diverter station provides a means of remotely changing waste routings without exposing the waste piping for jumper changes. Thus, its operation is similar to a switchboard in that highly radioactive waste solutions can be remotely routed to a selected underground waste storage tank, to the AR Vault, or to the CR Vault. This is accomplished by means of diverter tanks within the diverter station. Transfer lines leading into the station terminate in the diverter tanks. The waste solution overflows the diverter tank through a movable spout into a funnel on a transfer line leaving the station. A routing change is made by moving the spout to the proper funnel. Positioning the spout is accomplished through a shaft that extends through the cover block to a handle located above the station. Since diverter tanks rely on gravity flow, the fiows are unidirectional and are limited to less than $150 \mathrm{gal} / \mathrm{min}$.

Both diverter stations have spare outlet and inlet lines. Also, the wastes normally routed through some diverter tanks are to flow only to certain lines. The holes in the index plates for the spare lines and for lines not normally used are maintained and locked in a manner that precludes positioning the diverter to these locations.

Each diverter station has a catch tank located below the diverter cells to collect any spillage. Since the catch tanks 
do not have cooling coils, any self-heating wastes accumulating in these tanks cannot remain there. Each catch tank is equipped with a pump and a water jet for moving any accumulated 1iquids to a diverter tank.

Several administrative control measures are used in the operation of the diverter stations. A record of diverter changes is maintained on log sheets. A board showing the current routings from the various diverter tanks is maintained in the tank farm control building. The diverter handles are padlocked into position on the index plate, and the padlock keys are kept by the tank farm supervisor.

SURVEILLANCE ACTIONS EMPLOYED

The primary objective of the underground waste storage tanks is to confine high-level liquid wastes. It is of paramount importance that surveillance be sufficient to detect a leak or unusual behavior at an early date to preclude or minimize any release of radioactivity to the environment. In general, leak detection is based upon several mechanisms: differences in inventory records, surveillance of the soil surrounding each tank, and accumulation of liquid from drainage channels under the tanks. Each tank farm exhaust stack is equipped for monitoring discharges of radioactivity to the atmosphere.

Nonboiling Waste Tanks

In the nonboiling tanks, the liquid level is measured week $1 y$ for inactive tanks, daily for active tanks, or more often if a leak is suspected. Leak detection is also supplemented with a system of vertical dry wells in each farm. The wells are $75-\mathrm{ft}$ deep and extend several feet below the tank bottom. An ion chamber is periodical1y lowered into each well to detect any radioactivity in the soil. Dry wells are checked monthly where the activity level is $<50,000$ counts per minute (cpm) or week $1 y$ if the activity level is $>50,000 \mathrm{cpm}$. Tests have shown repeatedly that 1 iquid migrates laterally in addition to vertically in the 
Hanford soils. Monitoring of the vertical wells should thus detect a leaking tank before the groundwater is contaminated. In addition, each farm has wells which extend to groundwater and which are sampled each month for radioactivity.

Boiling Waste Tanks

Although liquid level readings are taken at least daily on all boiling waste tanks, the measurements are not as precise as those taken on nonboiling tanks because of the constantly varying volume in the self-boiling tanks. Consequently, other leak detection techniques are also used. At A and SX tank farms, primary reliance is placed on a system of horizontal channels underneath each tank, through which an ion chamber is passed and which monitors the surrounding area.

During the monitoring of a lateral, the ion chamber is forced by compressed air to the far end of the lateral, then slowly retrieved by an attached cable. Gamma activity is shown on the monitor console together with the position of the probe. A recorder may be attached to the console to provide a scan showing activity and location in a particular lateral. Normally, the monitoring is conducted once per week at A and SX farms. Any lateral with activity greater than $20,000 \mathrm{cpm}$, however, is checked three times per week. If a leak is suspected, readings are taken daily.

Each A farm tank has three lateral tubes which pass about $10 \mathrm{ft}$ beneath the bottom of the tank. In addition, A farm has a secondary leak detection system which consists of thirty-nine 75-ft deep dry wells, located about the perineter of the six storage tanks. The dry wells are checked monthly when the activity level is $<50,000 \mathrm{cpm}$ or weekly if $>50,000 \mathrm{cpm}$.

At the SX farm, all but one of the tanks which are equipped to handle boiling waste are serviced by three laterals $10 \mathrm{ft}$ below the tank bottom. The 113 tank has five such laterals. 
There are also forty-nine $75-\mathrm{ft}$ deep dry wells drilled around the periphery of the tank farm which are monitored for radioactivity on the same schedule as A farm.

Each AX farm tank has a system of drain channels and a collection well as described on page 22 . Temperature, weight factor, specific gravity, and radiation detection sensing elements for these systems read out in the AX farm instrumentation enclosures, and off-standard conditions sound an alarm in the tank farm control building. Weight factor and radiation readings for leak detection are taken daily. Each well is surmounted by a pump pit which permits the installation of a pump to remove any leakage detected.

Surveillance of the AY tanks now being built will be very similar to AX tank procedure. The monitoring facilities previously described on page 23 will be used to determine if waste liquids are entering the annular space between the two steel tank liners.

As the self-boiling tanks are filled with waste, the waste separates into a sludge layer and a supernatant liquid. Nearly all of the fission product decay heat is associated with the sludge. Heat is removed from the sludge by conduction and percolation of supernatant through the sludge, with percola. tion being the major mechanism for heat removal. As the sludge layer increases in depth and as the salt concentration in the supernatant increases with tank filling, it becomes more difficult to remove heat from the sludge. Thus, the sludge temperatures must be monitored and controlled, to the extent possible, to avoid exceeding the recommended structural temperature limits of the waste tank. The operating temperature of the waste supernatant should be maintained between $220^{\circ} \mathrm{F}$ and $250{ }^{\circ} \mathrm{F}$. The maximum sludge temperature should not exceed $300^{\circ} \mathrm{F}$.

Temperature measurements are made daily. Selected data are then graphically plotted and reviewed at least twice weekly 
to ensure continuous cognizance of sludge temperature trends. Temperature trends and the cause of the trend must be recognized promptly to permit remedial measures to be taken in time to avoid temperature excursions.

Al1 of the tanks in the $A$ and $A X$ tank farms are connected to a common vent header. As mentioned on page 19, the AY tanks will be tied in to this system. Each tank is connected to the 24-in. vapor header through a 20-in. vapor 1ine. In the A farm only, water seals are used to isolate nonboiling tanks from the vent system. The 20-in. vapor exits are baffled to reduce entrainment. Further vapor de-entrainment is achieved with a York demister in the 24-in. header. The de-entrained liquid is routed to a diverter station catch tank from which it can be sent back to the principal storage tanks. From the York demister, the vapors pass to three shell and tube condensers in parallel where the stream is condensed. The condensate is collected in a 40,000-gal underground carbon steel lined concrete tank from which it overflows to a crib or is returned to the boiling waste tanks to maintain the liquid level. The waste stream to the crib is sampled each shift, composited and analyzed monthly. Operational control is maintained, however, by taking a daily sample and analyzing it for gross activity. Condensate volume measurements permit calculations of the tank farmboil-off rate and determination of the volume of condensate returned to the individual storage tanks. The noncondensable gases pass through another York demister and then through high efficiency filters before being exhausted to the atmosphere. Each tank farm exhaust stack is equipped with a sample tap permitting the continuous sampling of gaseous effluent.

The normal water supply to the surface condensers is reused Purex waste cooling water. After the water passes through the condensers, a sample is withdrawn before it is combined with the remaining purex cooling water and flows to the Purex and $B$ ponds. The 8 -in. raw water 1 ine can be used as an emergency source of 
cooling water. Also, there is a cooling tower that can cool and recycle the condenser water. In addition, an emergency we11 is provided which will deliver about $100 \mathrm{ga} 1 / \mathrm{min}$ of makeup water. The condenser instrumentation includes a flow control system on the cooling water supply. The temperature differential between the feed and effluent water is used to control the flow rate.

Vapors generated by the heat of radioactive wastes in the SX tank farm are condensed in water-cooled condensers located in a condenser shield house. The vapor collection system consists of a header buried below grade and connected to each of the tanks. Vapors are carried via the header to Tk-106-SX where some condensation takes place and entrained liquids drop out. From this tank, the vapor is conducted to the condenser shield house via a 24-in. header. An exhauster (blower) has been installed on the vapor header to provide a slight vacuum on the vapor manifold system.

Valves in the condenser shield house route the vapors to any or all of four parallel primary water cooled condensers. From the primary condensers, vapors are routed to either or both of two parallel secondary condensers. Condensate flows to a condensate seal tank from which it overflows to the condensate return head tank. From the latter tank, which is sampled weekly, condensate may be routed to a crib through either or both of two rotameters, or it may be returned to the underground storage tanks.

Raw water enters the condensate shield house via parallel diaphragm-operated and manually-operated valves in a 6 -in. header. Valves route water through any or all of the condensers or route it in series through either or both of the two secondary condensers and then through any of the primary condensers. Water flow will normally be set with the manually-operated inlet valve. The diaphragm-operated valve receives signals 
from an effluent water temperature recorder-controller and supplies additional water in the event of surges from the boiling tanks. Effluent water is sampled weekly and routed to tiie U Plant pond via an 8-in. header and open ditch. 


\section{LEAK EXPERIENCE}

As previously discussed, 12 waste storage tank farms, totaling 149 tanks, have been built at Hanford during the last 25 years. Eleven tanks located in four of the farms are confirmed leakers. The different types of wastes handled, the different thermal conditions prevalent, and the small number of leaks encountered make it difficult to directly compare the tank failures which have occurred. While there are several theories regarding mechanisms for failure, including stress corrosion cracking and mechanical tearing of the liner, the extreme difficulty of direct inspection makes it impossible to accurately characterize the failures. There is, in all probability, more than one mechanism responsible.

Shifting of a tank liner was observed in 1956 and again in 1958, but no leak was confirmed until 1959. The frequency of tank failure averaged one per year until 1965 and has since declined. Only one failure has occurred since that time, however, a number of tanks are being closely monitored at present to determine the significance of liquid level variations over a period of several years. The decrease in the tank failure rate is probably at least partially due to increasingly stringent tank operating limits. These revised limits are a result of structural studies made on the tank, particularly in the area of thermal stressing (see Addendum).

A new design feature to reduce the likelihood of waste escaping to the environment has been included in tanks currently under construction. Two steel liners, instead of one, are being used within the concrete shell. The annular space between these liners will contain any material which might pass through the primary barrier.

Over the past several years, a number of improvements in leak detection capability have been developed and employed to permit the earliest possible recognition of conditions requiring special operating control actions.

The first boiling waste tank farms included ground water wells and a few dry wells for monitoring purposes. However, these 
were limited in number. The next step was the installation in December 1958 of a prototype horizontal lateral system under the 113-SX tank as a means of confirming a suspected leaking condition. This method of detecting leaks proved to be successful and similar systems were subsequently installed beneath all the boiling waste tanks in the SX and A tank farms during 1961. At this time, additional dry wells were also installed. The latest improvement in leak detection has been the incorporation of drain channels and. sump collection wells in the AX tank design.

Tanks storing nonboiling wastes have always been equipped with liquid level measurement devices which provide indication of changes in tank contents. The original nonboiling waste tank farms also included dry wells and wells to groundwater. Additional wells, however, have been drilled in strategic locations throughout various nonboiling waste tank farms as a result of tank leakages.

A summary of the tank leaks which have occurred is presented in Table 3 and some historical detail on each leaker concludes this section. Four of the eleven tanks in which leaks have occurred have contained nonboiling waste; the rest stored boiling waste. Seven of the eleven tanks have been probed to determine the location of the tank liner. These included tanks both in nonboiling and boiling service. Six have had a bulge. However, experience indicates that bulging tends to be a dynamic phenomenon, and it is possible that the one tank with no demonstrated bulge may actually have had a displaced liner at one time; observation of this one tank continues. Six of the eleven failed tanks have been emptied and refilled more than once.

The circumstances surrounding underground waste storage tank leak experience are detailed below for each such tank in the chronological sequence in which these leaks developed or were first suspected. 
TABLE 3. Underground Waste Storage Tank Leak Experience

Tank Built $\underline{\begin{array}{l}\text { First } \\ \text { Used }\end{array}}$ Type of Waste Stored Service

104-U 1943-44 1947

Uranium recovery waste

113-SX 1953-54 1958 Redox waste

106-TY 1951-52 1953

101-U 1943-44 1946

Uranium recovery waste

105-TY 1951-52 1953 TBP waste

108-SX 1953-54 1955 Redox waste

w

$\begin{array}{lrll}105-A & 1954-55 & 1963 & \text { Purex waste } \\ 107-S X & 1953-54 & 1956 & \text { Redox waste } \\ 109-S X & 1953-54 & 1-955 & \text { Redox waste } \\ 115-S X & 1953-54 & 1958 & \text { Redox waste } \\ 112-S X & 1953-54 & 1956 & \text { Redox waste }\end{array}$

L

1956

1958

Boiling

Nonboiling

1959

1959

Nonboiling

Nonboiling

Boiling

Boiling

Boiling

Boiling

Boiling

Boiling
Reason for

Suspicion

Bulged liner

Bulged liner

Liquid level

measurements

Liquid leve 1

measurements

Liquid level

measurements

Soil radi-

ation

Soil radi

ation

readings

Soil radi-

ation

readings

Soil radi-

Liquid level

measurements

Liquid level

measurements

eak Confirmed Bulge Estimated

Bulge Volume of

by

Found

Associated water (1961)

Yes $55,000^{*}$

Ss-137, kC

8

readings (1959)

20,000

30,000

2

iquid level

.

23

Liquid level

measurements

Liquid level

35,000

4

measurements

Yes 3,400

17

Soil radiation Yès Small

readings

Soil radiation

readings

Yes

No further

evidence

No

Sma 11

$50,000 * * *$

readings

Soil radiation

readings

* Contained water at time of leak.

*** Contained $\mathrm{NaNO}_{3}$ solution at time of leak, also some residual supernatant solution. 
104-U Tank. The 241-U tank farm, built in 1943-44, is the only one of the original three tank farms in which tank leaks have been experienced. This tank first received wastes in July 1947 from the bismuth phosphate process. It was emptied during August 1953 in the normal course of operation. In 1954, it was refilled with wastes from the recovery of uranium by tributylphosphate (TBP) solvent extraction. The wastes contained little fission product decay heat and were discharged directly to the tank farm from concentrators in the U P1ant. The wastes stored were primarily sodium nitrate and the tank temperature registered up to $150^{\circ} \mathrm{F}$.

In 1956, while attempting to install a pump during the uranium recovery sluicing operation, tank farm personnel discovered a bulge in the tank liner. A shorter pump was installed and the liquid was removed from the tank. No liquid drop had been noted in the tank and no activity was detected in dry wells within the farm. In August 1956, a periscope inspection of the inside of the tank showed what may have been a rupture in the liner. A second monitoring of the bulge, several months after the tank had been emptied, indicated the bulge had increased in size.

Later, failures were noted in 113-SX, 106-TY, and 101-U tanks. This prompted a recheck of 104-U integrity. In August 1960, the empty tank was filled with water and the liquid level monitored until February 1961. This test confirmed that a small leak existed, and the liquid was removed.

113-SX Tank. The 241-SX tank farm was built in 1953-54 to store wastes generated by the Redox plant. The 113-SX tank first received Redox solvent extraction wastes (primarily sodium nitrate and aluminate) in February 1958. Shortly after waste was first routed to the tank, the bottom liner bulged but receded several days later. Since the integrity of the liner was in doubt, the 
contents were pumped to another tank after which the liner rose and fell several times.

A leak detection lateral system was installed during December 1958, but monitoring of the lateral system from January 1959 to August 1962 did not detect any activity. In October 1962, saturated salt solution was pumped back into the tank in an effort to characterize any leak which might have resulted from the bulge. In November 1962, the 113-SX tank was again emptied after the leak had been demonstrated both by liquid level drop and by detection of activity in the laterals.

106-TY Tank. The 241-TY tank farm was built in 1951-52, shortly before the startup of uranium recovery operations in the U Plant. The 106-TY tank first received high salt wastes from $U$ Plant (TBP process) in June 1953. Liquid level measurements taken during July and August 1959 indicated that a leak had occurred. This was confirmed by radiation readings taken at a depth corresponding to the tank bottom in dry we11s about $10 \mathrm{ft}$ from the side of the tank. These radiation peaks have not migrated downward more than $10 \mathrm{ft}$ since they were first monitored in 1959.

101-U Tank. This tank was first used for bismuth phosphate process waste in February 1946. These original wastes were processed through U Plant for uranium recovery, and the tank was reused for wastes from that process between 1952 and 1957. In January 1957, the tank was filled with Redox solvent extraction waste supernatant solution from the SX Tank Farm. Beginning in November 1959 , 1iquid level measurements indicated a small leak had developed and the tank. was removed from service. The leak could not be confirmed by soil radiation readings in existing wells which were more than $25 \mathrm{ft}$ from the tank.

105-TY Tank. This tank was first used for the storage of high salt TBP wastes in January 1953. In September 1960, 1iquid level measurements indicated there was a leak and the tank was removed from service in November. The leak rate was very small 
(less than 1 gal/min), and required several months observation before the leak could be confirmed.

108-SX Tank. This tank was first filled in November 1955 with Redox solvent extraction waste. In December 1962, activity was detected during a routine survey of the leak detection laterals under the tank, even though no drop in liquid level had been detected. It should be noted that agitation of the liquid within the tanks holding boiling wastes and the recycle of cool condensate make it very difficult to monitor small leaks via liquid level measurements. The activity in the laterals increased slowly for several months, then held constant until the fall of 1966, when it again began increasing. Interpretation of radiation readings in under-tank laterals is difficult because the source geometry and distance from the detector is unknown. A series of readings over a period of time was essential to avoid misinterpretation. The tank was isolated from other systems, the condensate fully recycled, and the liquid level monitored until the spring of 1967. It was then concluded that a small leak did exist and provisions were made to remove the supernatant solution from the tank.

The 108-SX tank was used as a prototype to demonstrate the feasibility of air cooling radioactive siuages. To monitor the sludge temperatures a series of thermocouples were installed in September 1967. These thermocouple probes penetrate the sludge to the tank liner. In so doing, it was determined that the 108-SX liner had bulged. Activity has been found about $20 \mathrm{ft}$ below the 108-SX tank, the farthest migration noted bentath any of the leaking tanks.

105-A Tank. The 241-A tank farm was built in 1954-55 to store waste from the Purex plant. Beginning in February 1963, the 105-A tank received neutralized Purex solvent extraction waste. Activity was detected in the leak detection laterals below the tank in November 1963. The activity levels increased for several months, 
then became static. It was assumed the leak had self-sealed. A bulge was detected in the liner in the fall of 1965, and in April 1967 periodic liquid level fluctuations began to occur. They were attributed to the movement of solution into and out of the space between the bulged liner and the concrete bottom through a break in the liner. The liquid was removed during the FebruaryJune 1968 period, and most of the sludge was removed by sluicing during the following August-october period. Photographs taken within the tank confirmed the existence of a bulge and a hole in the liner. No additional radioactivity has since been detected in the leak detection wells and laterals.

107-SX Tank. This tank was first filled in April 1956 with Redox solvent extraction waste. Activity was detected both in the laterals beneath the tank and in the wells surrounding it in March 1964. Apparently the leak self-sealed (this has occurred in other tanks containing boiling waste) and the tank stayed in service until early 1967. At that time activity measurements in the laterals again rose. The supernatant liquid was removed and the remaining sludge is now being air cooled.

109-SX Tank. This tank was first filled in september 1955 with Redox salt waste. The supernatant was transferred to nonboiling waste storage as soon as its heat generation characteristics allowed. The tank was then refilled in 1964. In January 1965, activity was detected in the laterals beneath the tank. After the first rise in activity, no further increases were recorded, and the leak has since been considered to be inactive. Thermocouples have been installed in the tank and the liner elevation mapped. There is at present no bulge. The liquid level has been lowered to reduce the hydrostatic load on the sealed leak while at the same time keeping the sludge covered. As soon as funds are available, the remaining liquid will be removed and the sludge air cooled.

115-SX Tank. This tank was first filled with Redox solvent extraction waste in September 1958. The supernatant solution 
was pumped to nonboiling waste storage tanks after about $4 \mathrm{yr}$ of aging. Water was then added to leach the sodium nitrate from the sludge for recycling to the Redox plant. About 50,000 gal of the leached sodium nitrate solution leaked from the tank several months after the water was added (February 1965). The leak was detected first by a liquid level drop and was subsequently confirmed by the detection of activity beneath the tank.

112-SX Tank. This tank was first filled with Redox solvent extraction waste in September 1958. It was subsequently emptied and the sludge leached for sodium nitrate. The second filling with Redox waste was begun in April 1966. In January 1969 a significant liquid level drop indicated a leak, but within $48 \mathrm{hr}$ the leak had apparently self-sealed. The waste supernatant in the tank was reduced to a minimum by transfer to other tanks, thermocouples were installed and the tank bottom was mapped. Interestingly, it took several weeks for the activity from the leak to migrate downward sufficiently to be detectable in the leak detection laterals $10 \mathrm{ft}$ under the tank. As funds become available the remaining liquid will be removed and the sludge air cooled. 


\section{RATIONALE FOR DECISION}

The accumulation and storage of high-level radioactive wastes as liquids or slurries in underground tanks involves four general types of hazards:

(1) The atmosphere and/or ground surface can become contaminated, either by spread of radioactive mists or particles or by volatilization of radionuclides (e.g., cesium or ruthenium) from self-heating sludges that could be exposed under accident conditions.

(2) Operating personnel can be exposed to ionizing radiation in the course of removing or repairing contaminated equipment or moving wastes from tank to tank under nonroutine conditions.

(3) Cracks can develop in the tank liner and shell, permitting waste liquids to percolate into the surrounding soil, or in the case of large volumes (>50,000 gal), into the groundwater.

(4) The tank can in time be weakened to the point of structural failure with complete loss of confinement barriers.

Foreseeable mechanisms that could create these conditions have been studied extensively, and operating procedures and limits have been designed to minimize the probability of such conditions developing.

Despite our best efforts to maintain waste storage operating conditions within desired limits, situations sometimes arise that require corrective action to restore a position of minimum risk. While each off-standard situation must be analyzed and corrected individually, the major factors and guiding principles to be considered in formulating an action plan can be identified in advance. Typical situations requiring concerted management attention are discussed briefly below. 


\section{SLUUDE TEMPERATURE ABNORMALLY HIGH}

Recognition: Recorded temperature above $300^{\circ} \mathrm{F}$. *

Probable Cause: Loss of liquid percolation through sludge; blockage caused by. one or more of the following conditions:

- Overconcentration of soluble salts; experience has shown that five to six molar sodium concentration is a practical working limit, depending on other conditions existing.

- Higher than normal accumulation of salts having low or retrograde solubility; i.e., sulfates, carbonates or bicarbonates from organic wash, radiolysis of complexants, reaction of $\mathrm{CO}_{2}$ from airlift circulators with hydroxyl ion in waste.

- Deposit of sludge from fresh waste on top of aged, compacted wastes.

\section{Principal Considerations}

- Assuming that the rate of temperature rise is not enough to create an excessive thermal gradient in the tank walls, the condition is not immediately critical.

- Since deposition and leaching of salts by percolation through a sludge layer are controlling mechanisms, response to system changes is slow.

- The fraction of total heat generation associated with the insoluble components of the waste varies from about $98 \%$ for fresh waste to about $50 \%$ for aged waste. The fraction of solid materials remaining in suspension declines from the order of half to practically none in a few years.

\footnotetext{
$300{ }^{\circ} \mathrm{F}$ is at least 200 to $300^{\circ} \mathrm{F}$ below the temperature at which real trouble could develop; e.g., nitrate decomposition, structural weakening of tank, fission product volatilization, etc., but reflects the fact that liquid has been driven from that portion of the solids thereby significantly decreasing heat transfer capability.
} 


\section{Basic Approach}

Add water to the tank liquid level limit. Hold at maximum dilution to facilitate the leaching of soluble material from the sludge layer. This action is normally sufficient to cause the temperature rise to taper off to zero in 2 to 7 days and to return to normal within 2 months. The volume of supernatant would be kept high to minimize fluctuations of salt concentration and hence avoid inhibiting the leaching action. Mixing would also be facilitated by increasing the air flow through the circulators.

- If the above action does not check the temperature rise, some fraction (say $1 / 4$ to $1 / 2$ ) of the supernatant would be pumped to another tank and the heel diluted with water to maximum permissible volume. This step has never been necessary. It would be repeated, if necessary, to start a downward temperature trend.

- If the temperature continued to rise past $500^{\circ} \mathrm{F}$, the strength of the concrete shell would become questionable. If the temperature profile and history indicated that normal cooling by percolation could not be reestablished, the supernatant would be pumped to a heel just sufficient to cover the sludge, thus minimizing the potential for leakage to the ground in case of structural failure. Water would be added regularly to maintain liquid cooling to the extent possible. Personnel and equipment would be kept off the tank. 
LEAKING TANK - NONBOILING WASTE

Recognition: Declining liquid level as revealed by tank liquid inventory measurements; detection of radiation in nearby wells.

Probable Cause: Stress corrosion cracking of the carbon steel liner or a bulged liner.

Principal Considerations

- The greatest hazard in this situation is the transport of radiocesium through the soil with percolating supernatant. All radionuclides of concern other than cesium are essentially insoluble and are associated with the settled solids in the tank.

- The concrete structure and surrounding soil will act as a filter to hold the solids mechanically within the tank or in its immediate vicinity.

- The soil liquid retention characteristics are such that at least $50,000 \mathrm{gal}$ of liquid can be released from a point without percolation to the groundwater; with the ion exchange capacity of the soil, a leak of much greater magnitude would not contaminate the groundwater.

- The concentration of radionuclides in nonboiling supernatant is low enough that piping changes and pump installation can be performed quickly with minimal exposure of operating personnel to radiation.

Basic Approach

- Initiate action promptly to pump liquid contents from leaking tank to a sound tank. Pump to minimum liquid heel over sludge layer, usually within 10 days. Residual heel of liquid is normally less than 30,000 gal. 

between she11 and footing during operation. These cracks are prevented from becoming large ( $>1 / 4$ in. wide), however, by the restraining action of the reinforcing steel.

- The soil surrounding a tank containing self-boiling waste is an effective insulator and is normally only a few degrees cooler than the waste. In a tank containing settled solids with a high heat generation rate, sludge temperatures will be 250 to $290^{\circ} \mathrm{F}$, and the temperature of the soil may be at or slightly higher than the boiling point of the supernatant (about $230^{\circ} \mathrm{F}$ ).

- The salt concentration in a self-boiling waste is high, and evaporation of a significant amount of water causes crystal1ization. As supernatant starts to seep through cracks in concrete or the surrounding soil, water is evaporated by the heat from the liquid itself and from the concrete and soil. Such a system tends to self-seal with minimal leakage.

- Several considerations are associated with removing the supernatant from a sludge layer of "fresh" waste producing several million Btu/hr.

- The risk of exposing personnel to ionizing radiation during the preparation and pumping operations is significant.

- The solids transferred with the supernatant may settle and form a "blanket" on aged solids in the receiving tank. Depending on the age and characteristics of the aged and fresh solids, a temperature excursion may be triggered in the receiving tank. This situation would be encountered on $1 y$ if it were necessary to pump the supernatant to a tank containing aged sludge.

- Heat removal from the remaining solids layer requires liquid percolation. (conduction cannot be sufficient to dissipate more than about 50,000 to $100,000 \mathrm{Btu} / \mathrm{hr}$ ). 
- The salt concentration of the liquid must be kept high enough to avoid opening any self-sealed cracks and low enough to avoid crystallization within the settled solids. A concentration of five to six molar sodium appears optimum. The ability to control salt concentration in the supernatant varies inversely with the volume of supernatant present.

- Most tanks removed from service have had bulges in the bottom 1 iner.

- The act of removing liquid from a tank changes the stress on tank components. Since the effects of stress change on a distorted liner cannot be predicted with confidence and could be adverse, one must be fully prepared to control the temperature of residual solids by whatever means necessary when supernatant removal is started.

- With fresh waste the likelihood of self-sealing and the hazards of uncovering the self-heating solids are high. The hazards of emptying the tank decline with time while the hazards of cesium-laden supernatant percolating to the groundwater remains nearly constant.

\section{Basic Approach}

- The salt concentration in the supernatant is held in the upper part of the range deemed necessary to avoid a temperature excursion (ca., 6 molar sodium).

- Pumps, 1ines, and receiving tanks are prepared immediately for use in case transfer of solution is judged to be necessary.

- If the rate of self-heating in the sludge is high (greater than a few hundred thousand Btu/hr), an emergency spray system is prepared for use in keeping the sludge wet with 
a minimum of water if such an approach proves necessary.

- Radiation and temperature readings in wells and laterals are analyzed to determine the extent and rate of change of radionuclides in the soil. Pertinent factors include the following:

- A sharp peak of radiation (with respect to length of we 11 or lateral) denotes a trickle of waste close to the point of measurement.

- A broad zone of radiation may indicate either a broad zone of contamination or a trickle at some distance from the point of measurement. Since the predominant gamma emitter is ${ }^{137} \mathrm{Cs}(0.66 \mathrm{MeV})$ calculations can establish the parameters of the possible extents and intensities of contamination.

- A localized temperature increase would indicate a zone of soil plugged with dried self-heating salts.

- Assuming the above data indicate that significant quantities of seepage have not passed the we11/1ateral system and the rate of change is slow, the system is observed closely with daily readings of temperature and radiation. To date all such systems have self-sealed.

- Assuming self-sealing as indicated by a stabilization of radiation readings, the system is held as constant as possible.

- When the rate of self-heating in the sludge layer declines to a few hundred thousand Btu/hr, the supernatant is pumped to a sound tank and the residual sludge is cooled by an air purge, or water spray, if necessary. 


\section{ADDENDUM}

STRESS AND STRENGTH ANALYSIS FOR WASTE TANK STRUCTURES

ARHCO selected R. Eben Vey and Professor K. P. Milbradt of the Illinois Institute of Technology to determine the maximum storage capacity of the existing underground waste storage tanks and to establish their integrity for reuse. It was believed that additional storage capacity might be made available by increasing hydrostatic head limits if it could be shown that the active and passive resistance of the soil, not heretofore considered, would relieve stresses superimposed with load parameters.

Soil Loads

Three categories of soil loads, each acting in a unique manner on the tank, are considered here.

\section{Active Soil Loading}

Active soil pressures on the waste tank cylinder were established at $1 / 3 \mathrm{ry}$. The soil density is " $\gamma$ ". while the depth below ground surface is "y."

The active soil pressure over. the dome was established as the dead load of the soil at 110 1b/ft ${ }^{3}$. A smooth transition of soil pressure from the cylinder to the dome was accomplished by combining the $1 / 3$ ry function with the ry function for the various surface angles around the haunch region.

\section{Reactive Soil Pressure}

The waste tanks expand laterally against the backfill and encounter "reactive" soil pressures. A reactive soil modulus of 15 to $35 \mathrm{psi} / \mathrm{in}$. was used, depending on the confining pressure (depth).

The study concluded that the variations of active and reactive soil pressures on the cylinder do not constitute a 
major factor in the structural behavior of the waste tank. (This will be discussed later.)

\section{Footing and Slab Pressures}

The reactive soil pressures under the footing and slab depend on the deflections of footing and slab into the soil. These deflections are created by the active and reactive soil temperature loadings. Footing and slab deflection and rotation are governed by a combination of active and reactive soil pressures, hydrostatic head, thermal expansion, and cylinder horizontal rotational restraint. These variables created a nonlinear problem that was then solved by a computer program. The footing and $\mathrm{s} l \mathrm{ab}$ reactive modulus was established at 20,000 psi/in.

\section{Temperature}

Temperature forces occur during both steady and transient tank heatup modes of operation. In reality, a transient gradient affects the structure in the same manner as a steady state gradient. The difference is that a transient gradient changes with time. Thus, in order to determine the critical transient gradient several time periods had to be investigated.

Typical steddy state axisymmetric temperature distributions between sludge and liquid for the boiling waste tanks are 300 and $240^{\circ} \mathrm{F}$, respectively. These temperatures create some undesirable stress conditions which will be discussed later under "Combined Stress Evaluation." Temperature levels were varied in the analysis to determine safe values.

Two types of forces are generated by thermal gradients. One is caused by differential expansion of various parts of the waste tanks as they are heated from an ambient to a terminal temperature. This case applies particularly where the hotter base slab attempts to push the relatively cooler exterior footing and cylinder outward. The second force type is caused by a 
through-the-wall thermal gradient. This gradient expands. the inner surface of the waste tanks while the outer surface expands to a lesser degree, thus causing internal stress.

Thermal forces, the most predominate forces experienced by the waste tanks, often cause cracks in the concrete shell and high stresses in certain steel reinforcements.

Hydrostatic Head and Specific Gravity

Depending upon their density and depth, stored materials impart various outward forces against the steel tank liner and the concrete cylinder. These forces vary from zero at the liquid surface to a maximum at the tank bottom, depending on the specific gravity of the stored materials which range from 1.2 to 1.8 .

Vapor Pressure and Vacuum

Bumping in high level tanks releases superheated steam into the vapor space. This pressure is released by a seal loop at 60 in. of water equivalent.

A slight vacuum is held on all boiling tanks to keep condensate from escaping through tank openings and risers. This pressure is controlled by a 6 -in. water equivalent seal loop in the waste tank condensate lines.

Earthquake Induced Forces

The dynamic response of the waste tanks to earthquakes determines the distribution of forces in the horizontal and vertical directions. Vertical movements of the slab could shear it from the footing and cause liquid waste leakage, assuming concurrent liner failure. This vertical loading also causes additional inertial dome forces, while horizontal forces cause a sinusoidal loading on the side of the waste tanks and additional liquid is forced through by sloshing. The current Operating Basis Earthquake (OBE) is $0.12 \mathrm{~g}$ at zero period. The vesign Basis Earthquake (DBE) is $0.25 \mathrm{~g}$ at zero period. 


\section{COMBINED STRESS EVALUATION}

Hoop Tension at Cylinder Footing Juncture

of all forces considered, the thermal load was predominant. The combined liquid head and vapor pressures never exceeded the counteracting active plus reactive soil loads. All tanks can be filled to capacity. with little increase in stress. As head pressure increases, it becomes more critical with regard to leakage only when the concrete is cracked and the liner is ruptured.

Soil loading does not significantly affect the hoop concrete fracture at the juncture of cylinder and footing. This conclusion includes the active as well as the reactive soil loads caused by cylinder expansion.

Yielding of the reinforcement steel in the footing extension is indicated for the hoop direction for all cases examined.

In each case studied, sludge temperatures greater than $130^{\circ} \mathrm{F}$ created fractures in the footing extension. The fractures extended through the footing thickness and may possibly extend from the outer footing perimeter to the tank cylinder. The analysis showed that for steady-state sludge temperatures over $250^{\circ} \mathrm{F}$, through-thickness tensile fractures of the cylir.'er are probable. At sludge temperatures of $300^{\circ} \mathrm{F}$ and greater, severe tensile fractures occur which are probably large enough to allow leakage through the cylinder and footing.

However, the analysis thus far indicates that even if leakage through the concrete should occur, it would be relatively slow through fractures of less than 0.010 in. in width. These fractures should be well spaced near the base of the cylincer and join initiation fractures that start in the footing. 
Bending Stresses at Juncture

Meridional bending stresses do not cause tensile fractures in the concrete that would lead to leakage problems. These stresses are secondary in comparison to the "hoop" tension caused by thermal stresses.

Possible Shear-Tension Fracture of Cylinder

High temperatures in the base slab and outward displacement combine to create a shearing stress in the lower cylinder wall (24 in. above the footing). Using an allowable interaction shear stress value of 177 psi for 3000 psi concrete, the study showed that, in most tanks, shear fracture should not occur. At $350^{\circ} \mathrm{F}$ sludge temperatures, most of the tanks approach the upper limits of shear strength. It is probable that other fractures may precede the shear fractures, reducing the cylinder stiffness and also the shear stress.

\section{Dome Loads}

In the haunch region of the dome, axisymmetric steady-state temperature loading does not create significant stresses. The soil loads over the dome do cause noteworthy "hoop" tension and bending stresses in the reinforcing steel for the haunch region. These stresses, however, indicate an uitimate load safety factor of more than 4.0 , based on soil and concrete loads over the dome. Insignificant through-thickness "hoop" fractures are indicated for the concrete in the haunch region. The remaining regions in the dome are stressed to levels well below the allowables for concrete and steel as given by the ACI 318 code.

The only factor that could affect dome load limits is possible deterioration of the concrete by chemical attack or other unknown means.

Existing waste tank dome load limits are adequate to provide the safety necessary to achieve functional operations. 
MODEL TESTS, EXPERIMENTS AND OBSERVATIONS

105-A Scale Model of Bottom Liner

In an attempt to determine the manner in which the steel liner bottom in the $105-\mathrm{A}$ tank buckled to a maximum height of $8.5 \mathrm{ft}$, a scale model (0.096-to-1) was designed and tested. The model was designed to demonstrate that the bottom instability of the waste tank was caused by a steam pressure greater than the hydrostatic head. In the actual tank, however, the source of the steam was water driven from the cement grout and heated by the contents of the waste tank:

The model was pressurized until it failed. The differential pressure at failure was 0.63 psig and the maximum bulge height was $4-5 / 8$ in., corresponding to 48 in. in the actual tank. The tank bulge resulted from the side of the tank bending in below the first stiffener. Final failure resulted in a 2 -in. rupture of the cylinder bottom-plate connecting joint.

Theoretically, the actual tank should bulge at the same pressure as the model. Actual tank deflection is equal to the model tank deflection divided by the scaling factor. The model demonstrated that, in an actual tank, a saturated steam temperature of $251{ }^{\circ} \mathrm{F}$ would be sufficient to overcome the $15 \mathrm{psi}$ of liquid head in the tark and supply the 0.63 psig necessary to bulge the tank.

\section{8-SX Footing}

An exploratory caisson extending to the concrete footing of the waste tank was installed. Two 6-in. diameter cores were taken. Compressive strengths were between 5000 and 6000 psi. Inspection of the cylinder and footing of the waste tank revealed quite extensive cracking quite similar to that predicted by theoretical computations. Otherwise, the concrete appeared sound except for the hoop load tensile fractures. 
Radiation measurements were obtained as follows: $500 \mathrm{mR} / \mathrm{hr}$ under the footing, $5000 \mathrm{cpm}$ on the bottom side of one core, and $150 \mathrm{mR} / \mathrm{hr}$ at the bottom of the caisson.

A crust $1 / 4$ to $1 / 2$ in. deep, measuring $500 \mathrm{c} / \mathrm{m}$ was chipped from the top of the footing. A sample analysis revealed the following:

\begin{tabular}{|c|c|c|}
\hline & Sample & Normal Soil \\
\hline $\mathrm{pH}$ & 9.6 & $7-8$ \\
\hline $\mathrm{NO}_{3}$ & $0.4 \mathrm{mg} / \mathrm{g}$ & Significantly Less \\
\hline${ }^{137} \mathrm{Cs}$ & $2 \times 10^{-4} \mu \mathrm{Ci} / \mathrm{g}$ & 0 \\
\hline
\end{tabular}

These data indicate a small leak through the cylinder in the vicinity of the caisson.

101-A and 107-SX Dome Cores

Three concrete cores were taken from the dome of the 101-A tank to provide additional risers to checkout and effect prototype waste tank sluicing methods. An inspection of the cores revealed that two had structural cracks on the top side which extended through the concrete to a 10-in. depth in both principal stress directions. Further investigations revealed that the 101-A tank had been initially heated at a rapid rate. A transient heat transfer analysis was made and integrated into a combined thermal and static load stress analysis. This indicated that the dome could be cracked on the top side in a manner similar to that found during the core inspection. Later, two 12-in. diameter cores were taken from the dome of the 107-SX tank. These also had cracks equal in depth to those taken from the 101-A tank.

Mr. A. L. Parme, an expert in concrete shell structures, studied the cause, extent and consequences of the cracks that had developed. This included a theoretical study at the Illinois Institute of Technology and a thermal cracking test in a microconcrete mode1. Mr. Parme concluded: "The capacity of the dome to withstand the design vertical load has not been diminished by , 
the presence of cracks. The amount of reinforcement provided in the meridional direction (radial) is sufficient to ensure that there is always enough moment of inertia or stiffness in the dome even as a cracked section to prevent buckling of dome; thus, the capacity will always be controlled by the compressive strength of the concrete dome."

Cores have been taken from the domes of 101-SX, 112-BY and 105-A. None of these cores have shown any cracking. Compressive tests have shown the concrete strength to range from 3500 to $7000 \mathrm{psi}$. Concrete strengths appear normal for these aged structures.

Micro-Concrete Scale Mode1 Tests

Several tests affecting dome load characteristics were made on a one-to-ten scale model of the 105-A tank before complete destructive testing. In the first test the model was subjected to four times the service load. A general yielding of the reinforcement occurred in the haunch area and the cylinder just below the haunch. External and internal cracking of the concrete occurred from hoop strain equivalent to one and one-half times the normal service load. These cracks then propagated in a meridional direction to either side of the dome tangency as the loads were increased to four times the service load. Concrete cracks from bending were evidenced on the inside wall of the cylinder at approximately three times the service load as the haunch deflected outward.

The model was then subjected to a high thermal gradient in order to induce cracks in the concrete in both principal stress directions. The model was subjected to a $120^{\circ} \mathrm{F}$ gradient through the dome. Cracks occurred somewhat as predicted. The model was then subjected to four times the dome service load in order to determine the effect of the induced cracking on load-carrying capacity. Deflections and strain did not change appreciably from the first test. The dome of the model was then perforated in an 
arrangement simulating the size and number of cored holes in the 105-A tank. The model was then subjected to a programmed loading of eight times the service load in an attempt to cause the dome to fail in a manner that would result in serious consequences if it were the actual tank.

General yielding and cracking continued in the haunch region with plastic hinges forming on the cylinder at the dome tangent point and upon the dome about 11 in. from the edge of the cylinder. The cracks induced by the thermal test did not connect to or change any patterns of stress. Likewise, this is true of the cored holes in the mode1. Failure occurred at 7-1/2 times the normal service load in a compression-shear failure mode at the plastic hinge on the cylinder just below the haunch. The failure plane was clearly evident around most of the model. Considerable hoop cracking occurred in the haunch as higher and higher dome loads were applied. It appears that the waste tanks have a safety factor adequate enough to sustain any equipment or other gravity loads that may be applied either deliberately or accidentally, providing that the concrete has not deteriorated from exposure to steam vapors or other unknown factors.

Stress Corrosion Cracking Tests

An investigation was conducted to evaluate the effect of welding method and subsequent stress relief treatment on the stress corrosion cracking tendency of ASTM A-515, Grade 60 carbon stee 1 plate in $5 \mathrm{M}^{-} \mathrm{NaNO}_{3}$ solution at $190{ }^{\circ} \mathrm{F}$. Weldment coupons were fabricated from $3 / 8$ in. and $7 / 8$ in. thick plate using metal inert gas, shielded metal arc and automatic submerged arc welding methods. After fabrication, coupons were subjected to one of three stress relief treatments: 1) thermal stress relief at $600{ }^{\circ} \mathrm{F}$, 2) thermal. stress relief at $1100^{\circ} \mathrm{F}$, and 3) vibrational stress relief. One set of control coupons received no stress relief. 
treatment. After 8 weeks exposure to the sodium nitrate solution, cracking had occurred at the welds in those coupons that had received no stress relief treatment and those that had received a vibrational stress relief treatment. Cracking was generally more severe in coupons fabricated from 7/8-in. plate by submerged arc welding. Slight cracking occurred in one coupon in the set that had been thermal stress relieved at $600^{\circ} \mathrm{F}$. No cracking was observed in the set of coupons that was thermal stress relieved at $1100^{\circ} \mathrm{F}$.

\section{1-A Leak Detection}

The 101-A tank has been used to store high level radioactive waste solutions. After supernatant and sludges in this tank were removed, several checks were made on the 1 iner and concrete for waste containment capability and structural integrity. Observations were made of the steel 1 iner and concrete dome using a periscope. Also, photographs were taken of the tank interior. No stress corrosion cracking or pit corrosion of the steel liner was apparent. Although the concrete dome had been cracked during a rapid heat up cycle, its strength to withstand design loads has not been compromised.

A leak test was made by filling the tank with $70{ }^{\circ} \mathrm{C}$ solution and observing the liquid level and temperature stratifications for a week. The tank exhibited no leakage over this interval.

\section{Future Evaluations}

The current studies have considerably increased our understanding of the Hanford waste tanks. Allowable load deformations on the domes of waste tanks have been defined to the point that safe operations can be maintained. Thermal stress problems and temperature control have been well defined in the steady state transient condition. Liquid head soil reactions and vapor pressure influences are al1 definable in combination with

\section{A. 10}


the previously mentioned loads. However, there are a few areas still needing attention. The state of stress of the reinforcement under al1 loading conditions is not known for cracked concrete. An orthotropic analysis is being computercoded which will define the mechanical properties of cracked, reinforced concrete sections. These properties, in turn, will be used to calculate the state of stress of cracked structural sections.

The effect of earthquakes on tank structures has been studied for the tank design employed in the AY farm. 'However, a more detailed analysis of each existing tank configuration is needed. The Illinois Institute of Technology is presently studying this problem.

Also under study at IIT is the effect of asymmetric dome loads whether they result from heavy equipment or from impact loads caused by dropping heavy objects such as pump pit cover blocks.

The transient heating effects on stress need further study. This analysis will provide better understanding of the effects on heat-up and cool down of tanks.

Perhaps the area needing the most attention and yet is the most difficult to analyze and monitor is the structural condition of reinforcement and concrete in the dome. The dome is the most important structural component of the waste tank. Therefore, future concrete integrity studies will include examination of concrete cores from the dome and other areas, in situ inspcctions, material tests for both physical and mechanical properties, and periodic elevation checks on dome control points. References

1. Prof. K. P. Milbradt and Dr. Eben Vey, IZIinois Institute of Technology, "Interim Summary Report - Stress and Strength Analysis for Waste Tank Structures," May 30, 1969. 


\section{DISTRIBUTION}

No. of

Copies

External

15

Atomic Energy Commission

Internal

o. J. Elgert

35

Atlantic Richfield Hanford Company

S. J. Beard (4)

R. P. Corlew/J. H. Warren

L. M. Richards

E. F. Curren

W. L. Godfrey

W. M. Harty

R. W. Harvey

P. Hatch

R. E. Roberts

W. C. Schmidt

H. P. Shaw (6)

R. E. Tomlinson

Central Files

Extra (9) 